\title{
Assessing Human Exposure to SVOCs in Materials, Products, and Articles: A Modular Mechanistic Framework
}

\section{Eichler, Clara M. A.}

2021-01-05

Eichler , C M A , Hubal , E A C , Xu , Y, Cao , J , Bi , C , Weschler , C J , Salthammer , T , Morrison, G C , Koivisto , A J , Zhang , Y, Mandin , C , Wei , W , Blondeau , P , Poppendieck , D , Liu , X , Delmaar , C J E , Fantke , P , Jolliet , O , Shin , H-M , Diamond , M L , Shiraiwa , M , Zuend , A , Hopke , P K , von Goetz , N , Kulmala , M \& Little , J C 2021

, ' Assessing Human Exposure to SVOCs in Materials, Products, and Articles : A Modular Mechanistic Framework ' , Environmental Science \& Technology , vol. 55 , no. 1 , pp. 25-43 . https://doi.org/10.1021

http://hdl.handle.net/10138/337570

https://doi.org/10.1021/acs.est.0c02329

unspecified

acceptedVersion

Downloaded from Helda, University of Helsinki institutional repository.

This is an electronic reprint of the original article.

This reprint may differ from the original in pagination and typographic detail.

Please cite the original version. 


\section{Assessing Human Exposure to Chemicals in Materials, Products and Articles:}

\section{A Modular Mechanistic Framework}

3 Clara M. A. Eichler, ${ }^{1}$ Ying Xu, ${ }^{2}$ Jianping Cao, ${ }^{3}$ Charles J. Weschler, ${ }^{4,5}$ Tunga Salthammer, ${ }^{6}$ Glenn C. Morrison, ${ }^{7}$

4 Yinping Zhang, ${ }^{2}$ Corinne Mandin, ${ }^{8}$ Wenjuan Wei, ${ }^{8}$ Patrice Blondeau, ${ }^{9}$ Dustin Poppendieck, ${ }^{10}$ Elaine A. Cohen 5 Hubal, ${ }^{11}$ Xiaoyu Liu, ${ }^{11}$ Christiaan Delmaar, ${ }^{12}$ Antti Joonas Koivisto, ${ }^{13}$ Olivier Jolliet, ${ }^{14}$ Hyeong-Moo Shin, ${ }^{15}$ 6 Miriam L. Diamond, ${ }^{16}$ Chenyang $\mathrm{Bi}^{1}{ }^{1}$ and John C. Little ${ }^{1 *}$

\section{MI, 28}

${ }^{1}$ Department of Civil and Environmental Engineering, Virginia Tech, Blacksburg, VA, USA

${ }^{2}$ Beijing Key Laboratory of Indoor Air Quality Evaluation and Control, School of Architecture, Tsinghua University, Beijing, China

${ }^{3}$ School of Environmental Science and Engineering, Sun Yat-sen University, Guangzhou, Guangdong, China

${ }^{4}$ Environmental and Occupational Health Sciences Institute, Rutgers University, Piscataway, NJ, USA

${ }^{5}$ International Centre for Indoor Environment and Energy, Department of Civil Engineering, Technical University of Denmark, Lyngby, Denmark

${ }^{6}$ Fraunhofer WKI, Department of Material Analysis and Indoor Chemistry, Braunschweig, Germany

${ }^{7}$ Department of Environmental Sciences and Engineering, Gillings School of Global Public Health, The University of North Carolina at Chapel Hill, Chapel Hill, NC, USA

${ }^{8}$ University of Paris-Est, Scientific and Technical Center for Building (CSTB), French Indoor Air Quality Observatory (OQAl), Champs sur Marne, France

${ }^{9}$ Laboratoire des Sciences de l'Ingénieur pour l'Environnement - LaSIE, Université de La Rochelle, La Rochelle, France

${ }^{10}$ Engineering Lab, National Institute of Standards and Technology, Gaithersburg, MD, USA

${ }^{11}$ Office of Research and Development, U.S. EPA, Research Triangle Park, NC, USA

${ }^{12}$ National Institute for Public Health and the Environment, Center for Safety of Substances and Products, Bilthoven, The Netherlands

${ }^{13}$ Institute for Atmospheric and Earth System Research (INAR), University of Helsinki, Helsinki, Finland

${ }^{14}$ Department of Environmental Health Sciences, School of Public Health, University of Michigan, Ann Arbor, USA

${ }^{15}$ Department of Earth and Environmental Sciences, University of Texas in Arlington, Arlington, TX, USA

${ }^{16}$ Department of Earth Sciences, University of Toronto, Toronto, ON, Canada

*Corresponding author: jcl@vt.edu; Phone: (540) 231-0836 


\section{INTRODUCTION}

37 Rapid prioritization of large numbers of chemicals in numerous building materials, consumer products and

38 other indoor articles (here collectively referred to as sources) has become an increasing focus of chemical

39 management strategies to protect humans from potentially harmful exposures. ${ }^{1-3}$ Although these

40 strategies emphasize the need for high-quality exposure data and validated, mechanistic (i.e., process-

41 based) exposure models, approaches for implementation are highly fragmented among countries, national

42 agencies and research institutions, as shown by Eichler et al. ${ }^{4}$ Despite the progress that has been made in

43 understanding the fundamental mechanisms governing indoor exposure to chemicals released from

44 sources, especially for semi-volatile organic compounds (SVOCs), we need to consider the "bigger picture"

45 within which this chemical risk management problem exists. ${ }^{2,5-8}$ This is especially important because the

46 number of chemicals and sources is increasing steadily, challenging the ability of traditional approaches to

47 keep pace because key emission and exposure parameters have only been measured for very few

48 chemical/source combinations. ${ }^{7,9,10}$ Potential approaches to facilitate the transition from hazard-driven,

49 single-chemical assessments toward rapid, risk-based prioritization are already being developed and

50 include procedures to estimate exposure, toxicity and toxicokinetics. ${ }^{3,11-16}$ For example, high-throughput

51 (HT) screening methods allow testing of large numbers of samples with highly automated instruments in

52 combination with advanced data processing software. ${ }^{12,17}$ Substantial efforts have been made in

53 advancing $\mathrm{HT}$ hazard information and $\mathrm{HT}$ toxicokinetics, ${ }^{18}$ but essential information to predict human

54 exposure to chemicals in indoor sources is often missing. ${ }^{19}$ To fully realize the potential of new chemical 
risk assessment approaches in the most useful and efficient way, reliable chemical exposure models have

56 to be employed in combination with quickly accessible toxicity data. ${ }^{2,20}$

57 The objective of this paper is to describe a generic modular mechanistic framework for predicting chemical emission from an indoor source, partitioning among indoor compartments and exposure to humans present in the indoor environment within a risk assessment context and focusing on SVOCs. This will be achieved by defining mechanistically-consistent source emission categories and describing exposure pathways that are congruent with these source categories and the subsequent chemical distribution among indoor compartments. The modular structure of the framework should make it possible to subsequently include other classes of chemicals released indoors. Its purpose is to serve as a tool for rapid risk ranking and screening for the general population, but excluding worker exposure.

Many of the specific elements and models forming the framework have been described elsewhere ${ }^{21-23}$, but to advance chemical risk assessment, it is necessary to combine and connect them in an agreed-upon way

67 that can be easily implemented. As the proposed framework evolves in an iterative fashion, the combination of exposure estimates with toxicity and toxicokinetic information will allow rapid estimation and ranking of risk for a wide range of chemical/source combinations, therefore providing consistent evaluations for policy decision-making and new insights for manufacturers.

\section{INITIAL FOCUS ON SVOCS}

There are several definitions of SVOCs. The World Health Organization (WHO) defines SVOCs as a group of

74 chemicals with boiling points in the range of $\left(240-260^{\circ} \mathrm{C}\right)$ to $\left(380-400^{\circ} \mathrm{C}\right) .{ }^{24}$ According to International

75 Standard ISO 16000-6:2011, SVOCs are eluting after n-hexadecane on a non-polar gas chromatography

76 capillary column ${ }^{25}$ Another definition refers to a vapor pressure range of $10^{-9}$ to $10 \mathrm{~Pa} .{ }^{26} \mathrm{SVOCs}$ are present

77 in many different consumer products, building materials and other indoor articles where they are used, 
78 for example, as plasticizers, flame retardants and pesticides. A large number of SVOCs have been 79 associated with adverse health impacts, making them of particular concern to scientists, chemical 80 managers and policy makers. ${ }^{27-30}$ Due to their physicochemical properties, quantifying SVOCs in indoor 81 environments is challenging because they tend to partition among indoor compartments (gas phase, 82 airborne particles, settled dust and surfaces) at different rates. ${ }^{31}$

83 SVOC emissions can occur during active source use (e.g., spraying of pesticides or application of varnish) 84 or passively (e.g., migration from plastic products such as PVC shower curtains). Exposure to SVOCs is 85 possible via inhalation, dermal uptake (i.e., transfer from a source to the skin surface) and ingestion. ${ }^{32}$ In $862006, \mathrm{Xu}$ and Little $\mathrm{e}^{33}$ were the first to extend a model originally developed for volatile organic compounds 87 (VOCs) to predict emission rates of SVOCs from polymeric materials. They showed that SVOC emission and transport are subject to external control, i.e. partitioning, convective mass transfer and adsorption to 89 surfaces and airborne particles. ${ }^{33}$ In 2008, Weschler et al. ${ }^{34}$ investigated the distribution of phthalates 90 among the gas phase, airborne particles and settled dust, and provided a model for the particle-gas 91 partition coefficient $K_{\mathrm{p}}$, which allows an estimation of the SVOC concentration in airborne particles if the 92 gas-phase concentration is known. Weschler and Nazaroff $(2008)^{26}$ then presented the first framework for 93 characterizing the equilibrium partitioning among indoor compartments for SVOCs. One key finding was

94 that SVOCs might persist in indoor environments for years, depending on their vapor pressure, even after 95 the original source has been removed. ${ }^{26}$ Several studies followed, presenting both measurements and 96 models describing SVOC emission, transport and subsequent exposure, often with a focus on phthalates 97 such as DEHP. ${ }^{35-38}$

98 In 2012, Little et al. ${ }^{31}$ proposed a framework for rapid exposure estimates based on the source type in 99 which the respective SVOC is present. Accounting for source composition and use as well as emission 100 characteristics, a simple method to estimate exposure for additives in sources used indoors and for sources 101 sprayed or applied to interior surfaces was developed. ${ }^{31}$ The key parameters needed for these models 
have since been investigated and reliable measurement methods are increasingly available, with different

103 levels of complexity. ${ }^{39-47}$ Other aspects, such as the influence of clothing on dermal SVOC exposure, ${ }^{48,49}$ 104 the previously underestimated dermal uptake of SVOCs from air, ${ }^{21,50,51}$ or the impact of organic films on 105 indoor surfaces on SVOC dynamics ${ }^{52,53}$, have been studied in increasing detail.

106 With this paper, and during the further development of the framework, we hope to create consensus 107 among researchers and stakeholders regarding SVOC exposure models, parameter estimation procedures, 108 assumptions, limitations and conditions of use. We do not intend to review SVOC exposure models in detail, as several recent reviews exist. ${ }^{21-23,54}$ The initial consensus points that underlie the framework and 110 the equations that comprise the initial version of the framework are provided in the Supplementary 111 Information (SI). The SI also provides a decision tree for identifying appropriate exposure scenarios based 112 on the framework.

\section{FRAMEWORK FOR PREDICTING EXPOSURE TO INDOOR SVOCS}

115 Figure 1 shows the mechanistic modeling framework to be used for estimating exposure to SVOCs emitted 116 from sources present or used in the indoor environment. The central elements of the framework are 1)

117 modeling of emission based on mechanistically consistent source categories, 2) modeling of transport, 118 chemical transformations (where applicable) and resulting concentrations in the respective indoor environmental compartments, and 3) estimating exposure via different pathways based on the 120 concentrations in the compartments for different exposure scenarios. In the following sections, we 121 describe the scientific background and underlying assumptions of the mechanistic models for emission, 122 transport, chemistry and exposure, as well as their main parameter needs, uncertainties, and limitations 123 and conditions of use. Availability and quality of input parameters impact the modeling outcome 124 significantly and thus represent starting points for further research and the integration of existing data 
125 sets, relationships and expert opinions intended to decrease uncertainties and improve the suite of 126 models.

127 Dietary exposure to SVOCs present in food and beverages is an important aspect of overall exposure to 128 certain SVOCs, for example for diethyl phthalate (DEP) and di-2-ethylhexyl phthalate (DEHP). ${ }^{55-57}$ To assess

129 this particular exposure pathway, a framework equivalent to that discussed here is necessary, but this is 130 considered beyond the scope of the current work.

Source Emission Categories

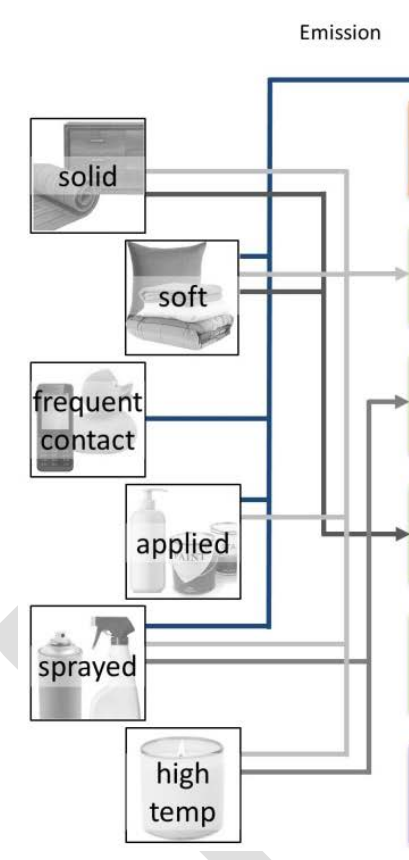

Environmental Compartments

Transport \& Chemistry

Outdoor contributions

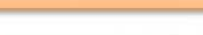

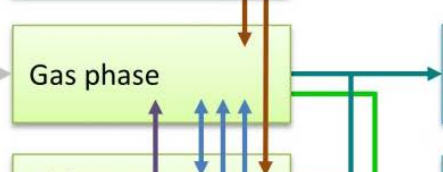

Exposure

Pathways

\section{Direct Exposure*}
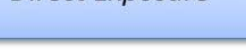

Dermal uptake
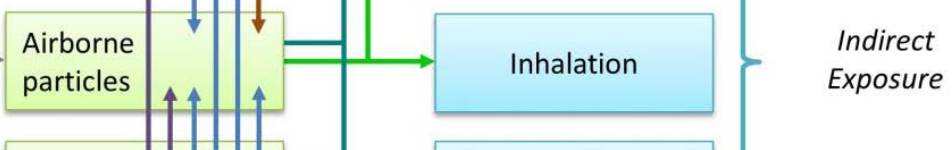

Ingestion

*Dermal uptake and ingestion including mouthing

133 Figure 1: A modular framework for modeling indoor SVOC emission, transport, chemistry and exposure.

135 In this framework, the focus is on mechanistic modeling as it resolves many of the key challenges posed 136 when predicting exposure. ${ }^{58}$ Mechanistic models, also referred to as process-based models ${ }^{19}$, rely on wellestablished physicochemical processes such as diffusion or sorption. They are generalizable and can be varied in complexity based on the needs of the assessment, in contrast to empirical models. ${ }^{54}$ However, if 
suitable mechanistic models are not available, other approaches such as machine-learning, expert opinions, statistics, or empirical models may serve in a preliminary role. ${ }^{59}$

\section{$142 \quad 3.1$ Assumptions}

143 The following general assumptions are often made for SVOC emission, transport and exposure models.

144 They are valid in many cases, but there are exceptions that increase the uncertainty of the derived 145 exposure estimates.

146 The indoor compartments considered in this framework are the gas phase, airborne particles, dust and

147 surfaces. We included clothing as an additional compartment because its role in exposure scenarios is 148 rather complex. ${ }^{48,60}$ Clean clothing has been shown to protect against dermal uptake of SVOCs from air, 149 while clothing that had been exposed to contaminated air increases dermal uptake. ${ }^{48,} 61$ These 150 characteristics together with other properties discussed below distinguish clothing from other 151 environmental compartments.

152 The assumption of equilibrium between gas phase, airborne particles, dust and surfaces is assumed for

153 most SVOC models because it eliminates some kinetic complexity. ${ }^{42,} 62$ However, the greater the capacity 154 an environmental compartment has for SVOCs, the longer it will take to reach equilibrium with other 155 compartments, in which case the use of models that include kinetics should be considered.

156 SVOC emissions from source materials are considered externally controlled, meaning that internal mass 157 transfer is much faster than external mass transfer. ${ }^{26,}{ }^{33}$ Furthermore, the material-phase SVOC 158 concentration $C_{0}$ can be considered constant as depletion happens at a much slower rate, as shown by Xu 159 et al. ${ }^{63}, \mathrm{Xu}$ and Little $\mathrm{e}^{33}$ and Pei et al. ${ }^{64}$. However, these assumptions are only valid for sufficiently small 160 external mass transfer coefficients and SVOCs with relatively low vapor pressures. Internal diffusion may 161 become important when considering transfer into clothing. 
162 It is generally assumed that the air in the indoor environment is well-mixed, but this may not be the case

163 for indoor air in confined spaces, for example within cabinets and closets.

164 In some cases it may be reasonable to assume that background outdoor concentrations of SVOCs are small

165 and thus negligible for exposure assessments of chemicals released by indoor sources. This assumption

166 depends on the type of SVOC considered, as some are present both indoors and outdoors, e.g., pesticides

167 and certain phthalates. ${ }^{65-67}$ If an SVOC has an outdoor source, the SVOC concentration in the infiltrating air

168 including particle-phase SVOCs should be taken into account.

$170 \quad 3.2$ Model Formulation

$171 \quad$ 3.2.1 Emission

172 The framework is structured to distinguish between Direct and Indirect Exposure (Figure 1). Direct

173 Exposure can occur immediately via direct dermal uptake or ingestion of the source. Alternatively,

174 emission from the source to environmental compartments occurs first, followed by partitioning and

175 chemical transformations, resulting in accumulation in one or more compartments from which exposure

176 occurs (Indirect Exposure). Chemical emission from a source depends largely on chemical characteristics,

177 on the source type and on the environmental compartment into which the chemical is emitted. ${ }^{31}$ However,

178 all indoor environmental compartments can serve as both sources and sinks, even simultaneously,

179 depending on the chemical and the direction of the chemical fugacity gradient. The general direction for

180 the context of this framework is the transport from sources with high fugacity to sinks (including humans)

181 with lower fugacity, thus the arrows in Figure 1 point from the left (sources) to the right (human exposure).

182 However, except for ingestion, the direction of the chemical fugacity gradient is reversible.

183 Classic emission sources are furniture, building materials including flooring and carpet, personal care 184 products, as well as combustion processes (e.g., burning a scented candle) and meal preparation (e.g., 
185 heating oil in a pan). For our modeling framework, we derived emission source categories from a 186 continuum of possible sources (Figure 2). We recognize that there is some overlap between the source categories and that some sources may not fit perfectly into one category. In such a case, multiple scenarios 188 could be considered.

189 For SVOCs, Little et al. ${ }^{31}$ differentiated between two main source categories. One included solid sources in 190 which SVOCs are present as additives and the other included sources containing SVOCs that are either 191 sprayed or applied, with mechanistic emission models presented for both categories. Here, we propose to 192 modify and extend the list to include the following emission source categories: solid sources, soft sources, 193 sources that humans frequently contact, liquid applied sources, liquid sprayed sources, and high 194 temperature sources, resulting in a total of six mechanistically consistent source emission categories 195 (Figure 2), which cover most sources containing SVOCs. ${ }^{9}, 68$ The saturation vapor pressure $p_{\mathrm{s}}$ (Eq. I in the $196 \mathrm{SI}$ ) and the octanol/air partition coefficient $K_{\text {oa }}$ (Eq. II in the SI) are fundamental parameters needed for modeling SVOC emission and partitioning. 

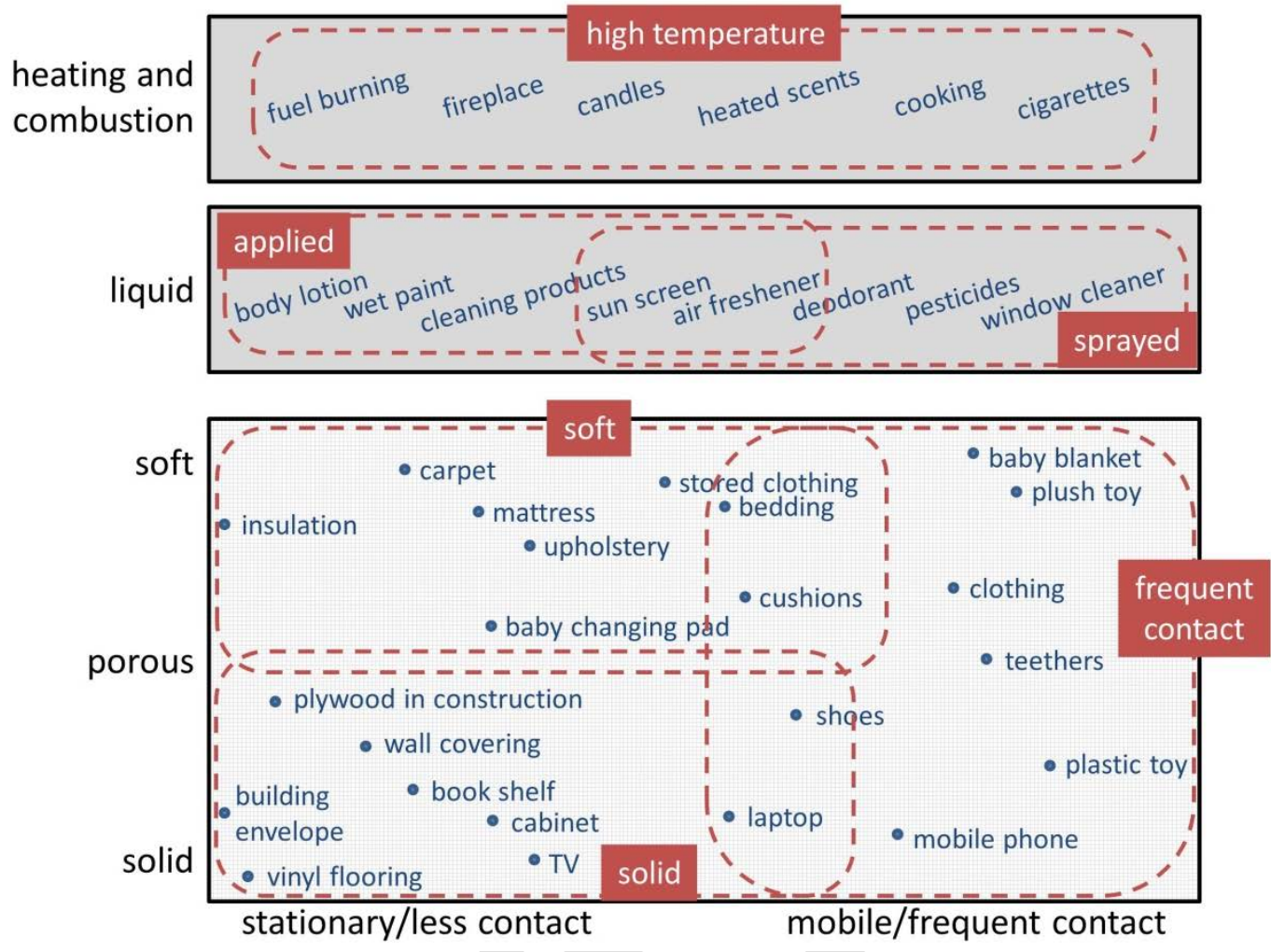

200 Figure 2: Classification of emission source categories from a continuum of possible sources, which range

201 from solid to soft, from stationary to mobile, and including certain specific uses such as applied, sprayed, and heated/combusted.

Solid sources containing SVOCs include, for example, PVC flooring, electronic devices such as TVs, plywood

206 furniture and painted walls. They have larger emitting surface areas relative to the volume of most indoor

207 environments or to the area that might come in contact with an exposed person. Exposure to SVOCs

208 present in these solid sources mainly occurs by Indirect Exposure. Direct Exposure contributes much less

209 to overall exposure. ${ }^{69}$

210 As discussed above, depletion of the SVOC in the source can often be assumed to be negligible. ${ }^{70}$ Including

211 the variability of source strength over time in the model increases its complexity, but the mechanisms 
212 governing emission from solid sources remain the same. A prerequisite for calculating the depletion rate

213 is that $C_{0}$ is known.

214 From a solid source, emission may occur either into the gas phase or by migration onto dust in direct

215 contact with the solid source material. ${ }^{31,71}$ Governing parameters for emission into the gas phase are the

216 SVOC gas-phase concentration immediately adjacent to the source material $y_{0}$ and the mass transfer

217 coefficient $h_{\mathrm{m}}$ (Eq. $1 \mathrm{a}$ in the SI). ${ }^{22,}{ }^{31} C_{0}$ also impacts the SVOC gas-phase concentration immediately

218 adjacent to the source material $y_{0}$ (Eq. III in the SI)..$^{43}$ If it is assumed that a linear equilibrium relationship

219 exists between the settled dust and the gas layer directly adjacent to the source material (Eq. 3 in the SI),

220 the critical parameters for modeling emission onto dust are $y_{0}, h_{m}$ (Eq. IV in the SI), the dust/air partition

221 coefficient, $K_{\text {dust }}$ (Eq. VI in the $\mathrm{SI}$ ), the particle deposition velocity $v_{\mathrm{d}}$ (literature values) and the

222 concentration of airborne particles, which is usually given as Total Suspended Particles, TSP (measured). ${ }^{22,}$

$223 \quad 35,72$

224 Soft Sources

225 Exposure to soft sources can occur both via Direct Exposure due to frequent close contact of a person with

226 these sources and via Indirect Exposure due to their often large emitting surface areas. Soft sources include

227 cushions, mattresses, foams, carpets and clothing. New clothing may contain SVOCs introduced during

228 manufacture, transport, storage, or from contact with packaging materials, or because they have been

229 added deliberately for product enhancement, for example water-resistant coatings. ${ }^{60}$ These SVOCs may

230 be emitted into the indoor environment after the clothing has been brought home and even after

231 laundering. ${ }^{60}$ Stored clothing may accumulate SVOCs from the air and thus serve as an additional

232 environmental compartment. ${ }^{48}$ Emission from soft sources into the gas phase or onto settled dust can be

233 modeled using Equations 1a and 3 in the SI, respectively.

234 Frequent Contact Sources 
236 or mouthed by children (e.g., teethers) is more likely to occur via Direct Exposure. These sources are not 237 stationary, usually irregularly shaped and their emitting surface area is comparatively small and thus 238 contributes less to the SVOC concentrations in the environmental compartments, but emission may be 239 modeled as for solid sources. ${ }^{60}$

\section{Applied sources}

241 A liquid source that is directly applied to the body (e.g., body lotion, shampoo, sun screen) is mainly linked

242 to Direct Exposure. With a liquid source applied to the body, emission into the gas phase and further 243 partitioning occurs, which may contribute to total exposure to some extent, depending on the SVOC and 244 individual behavior. ${ }^{73,74}$

245 If the liquid source is applied to a surface or remains open to the indoor air, Indirect Exposure dominates 246 for more volatile SVOCs. ${ }^{8}$ Examples are floor care products, other cleaning products, detergents, or wet 247 paint. Emission from an applied source is usually confined to a relatively short period of time during and 248 shortly after application. For this type of pulse emission, dynamic models are needed (Eq. 1b in the SI). For 249 certain cases, for example the application of paint, it might be necessary to look at the applied exposure 250 scenario first, and then to consider exposure from the solid source after the paint has dried.

251 After initial release, SVOCs partition onto sink surfaces (including exposed skin, hair and clothing), airborne 252 particles and dust, from where long-term exposure may occur even if the initial short-term source has 253 evaporated or been depleted. In the case of dried paint or similar dried sources, emission into the gas 254 phase can be modeled using the same approach as for emission into the gas phase from a solid source (Eq. $2551 \mathrm{a}$ in the $\mathrm{SI}) .{ }^{33}$ 
257 A liquid source that is sprayed towards the body can participate in both Direct and Indirect Exposure.

258 Dermal uptake by direct contact with the source occurs together with exposure by dermal uptake from air 259 and inhalation of both gas and particle phases. Examples are deodorants, perfumes, or spray sun screen.

260 If the source is sprayed away from a person, e.g., air freshener or window cleaner, Indirect Exposure 261 contributes more.

262 Sprayed sources are pulse emission sources with constant or variable time patterns. The emission 263 mechanism of sprayed sources differs from that of liquid sources because of the force with which the 264 product is released within a relatively small volume of air, resulting in high concentrations for a short 265 period of time. The formation of aerosol droplets which interact with airborne particles, dust and sink 266 surfaces enhances the potential for exposure which may occur long after the initial release. Additionally, 267 powdery sources may fall into this category, as their application can also emit high concentrations in a 268 short period of time and releases particles into the indoor air. Equations $1 \mathrm{c}$ and $2 \mathrm{a}$ in the SI describe 269 emission from sprayed sources into the gas phase and into the particle phase, respectively.

High Temperature Sources

271 High-temperature events like candle burning, cooking, or having a fire in the fireplace are pulse emission 272 sources that can release gas-phase SVOCs (Eq. $1 \mathrm{~d}$ in the $\mathrm{SI}$ ) as well as airborne particles (Eq. $2 \mathrm{~b}$ in the SI) 273 over a longer period of time compared to sprayed sources. ${ }^{8}$ In addition, chemical reactions (oxidation) 274 possibly happening during emission have to be taken into account. Exposure to these types of sources is 275 primarily indirect. Although all sources may undergo temperature variations that influence their chemical 276 activity and thus emission behavior, this particular category targets sources that participate in intentional 277 events and experience high temperatures for a certain period of time. 
Transport and chemistry of SVOCs indoors are highly complex and not yet completely understood. ${ }^{75}$

281 Individual indoor environments are almost impossible to depict completely with models. However, for the

282 sake of rapid risk assessment, a breakdown of basic transport mechanisms is possible and will yield useful

283 average results that allow risk ranking and prioritization. Our understanding of reactions and chemical

284 transformations that involve SVOCs is still limited. Thus, we will discuss indoor chemistry here only briefly

285 and qualitatively.

286 Particles either infiltrate from outdoors or are emitted by occupants and occupant activities. ${ }^{75}$ Gas/particle

287 partitioning is described in Equation 4 in the SI. Equation 7 in the SI shows the mass balance for particle

288 transport, taking into account particle infiltration and removal, deposition, dust resuspension, and particle

generation. Particle residence time and air change rate correspond directly. ${ }^{62}$ The lower their vapor

pressure, the more SVOCs tend to partition to particles or surfaces. For less volatile SVOCs, for which

instantaneous equilibrium between gas and particle phase is not likely, dynamic models exist that account

for particle residence times. ${ }^{62}$ For estimation of the gas/particle partition coefficient $K_{p}$, see Equation $V$ in

293 the SI.

294 Further partitioning may occur between the gas phase and dust settled on source surfaces (Eq. 5a in the

$295 \mathrm{SI}$ ) and on sink surfaces (Eq. $5 \mathrm{~b}$ in the SI). A mass balance for dust settled on sink surfaces can be found in

296 Equation 8 in the SI. See Equation VI in the SI for estimation of the dust/gas partition coefficient $K_{\text {dust }}$.

Clausen et al. ${ }^{76}$, Schripp et al. ${ }^{77}$ and Liu et al. ${ }^{71}$ focus on the kinetic process of SVOC uptake by dust particles and explore the relationship between the source surface and layers of settled dust. Dust may furthermore contribute to SVOC losses due to a combination of abiotic and microbial degradation, if the relative unusual exposure scenarios.

From the gas phase, SVOCs also partition to sink surfaces. The surface/gas partition coefficient $K_{\mathrm{s}}$ depends 
304 Equation $6 \mathrm{a}$ in the SI describes surface/gas partitioning for solid sink surfaces; Equation $6 \mathrm{~b}$ in the SI 305 describes surface/gas partitioning for soft sink surfaces with dust settled on those surfaces.

306 Further complexity to modeling the uptake of SVOCs by sink surfaces is added by including thin organic 307 films that are likely present on all indoor surfaces (Eq. 6c in the SI). Their presence affects SVOC dynamics 308 and is thus also relevant for modeling of partitioning onto surfaces, because the presence of organic 309 material on surfaces changes partitioning parameters, especially $K_{s}$. Weschler and Nazaroff ${ }^{52}$ studied the 310 growth of organic films on impermeable surfaces for SVOCs with different octanol/air partition coefficients

$311 K_{\text {oa }}$ and observed that SVOCs with a $\log \left(K_{\text {oa }}\right)$ between 10 and 13 were predominantly present in the film.

312 Furthermore, the growth rate of the film was initially high and decreased over time. Low molecular weight 313 SVOCs reach their equilibrium surface concentration relatively quickly, compared to higher molecular 314 weight SVOCs. ${ }^{21,52}$ Eichler et al. ${ }^{53}$ added a mass-transfer model that describes the initial formation of an 315 organic film on clean impermeable surfaces, identifying a two-stage process that requires the film to reach 316 a critical thickness before the growth model becomes applicable. This approach is supported by findings 317 from Liang et al. ${ }^{81}$ Coarse particle deposition on upward-oriented surfaces is also likely to influence the 318 growth of organic surface films, depending on the gas-phase concentration of SVOCs with higher $\log \left(K_{\mathrm{oa}}\right)$ values, the concentration of airborne particles and their fraction of organic matter. ${ }^{52}$

320 Equation 9 in the SI shows the general mass balance for indoor SVOCs. The elements of the mass balance 321 include infiltration of gas- and particle-phase SVOCs into the indoor environment, removal of gas- and 322 particle-phase SVOCs, SVOC emission from source surfaces, mass transfer to sink surfaces, deposition of 323 particles on source and sink surfaces, and resuspension of dust from source and sink surfaces.

324 Clothing has been identified in recent years as an important mediator of human exposure to chemicals 325 and particles, potentially acting as a barrier to exposure or having a prolonging effect. ${ }^{49,60}$ Newly purchased 326 clothing as an emission source has been discussed above. Post-purchase, clothing contains a mix of SVOCs 327 (among other chemicals) present at the time of purchase and those sorbed while stored or in use. ${ }^{60}$ Several 
studies have shown that SVOCs present in indoor air can accumulate in clothing. ${ }^{48,49,82-84}$ Partitioning between clothing and air can be modeled using Equation 10a in the SI. For very thin clothing, diffusion inside the clothing material can be ignored, and a simplified model can be applied (Eq. 10b in the SI). This can be described using the gas/clothing partition coefficient $K_{\mathrm{ca}}$, which can be approximated for cotton based on $K_{\text {oa }}{ }^{83}$ Morrison et al. ${ }^{82,83}$ and Cao et al. ${ }^{47}$ reported values for $K_{\text {ca }}$ for PCBs and phthalates in different types of clothing material (Eq. VIII in the SI). Additionally, clothing may take up SVOCs from personal care products applied to skin, from laundering detergents and dry-cleaning additives, and also from cross-contamination with other fabrics during laundering and storage. ${ }^{60}$ Partitioning between clothing and particles has only been studied to a small extent, but clothing can serve as a source of biotic and abiotic particles that may contribute to the particle mass balance indoors and thus to human exposure. Potential strategies to determine emission rates of particles from clothing can be found in Licina et al. ${ }^{60}$

Indoor chemistry involves thousands of species that undergo transformations, resulting in changes in gas

340 phase composition, and countless different indoor materials serve as sinks, sources and reaction sites. ${ }^{21}$

34185,86 Occupants change indoor chemistry as well, also serving as sinks and sources and providing surfaces

342 for chemical transformations. ${ }^{87}$ The formation of secondary organic aerosols (SOAs), i.e., the generation

343 of particles as a result of the oxidation of some reactive organic species in the gas phase by ozone, is an

344 important additional aspect to consider when evaluating gas/particle partitioning of SVOCs. ${ }^{88-90}$ However,

345 because of their reactivity and composition, SOA emission rates and their partitioning can only be assessed

346 using complex and detailed chemical models which are currently beyond the scope of the proposed

347 framework. ${ }^{91}$ Nevertheless, the possibility of the formation of SVOCs should be addressed at least 348 qualitatively as part of any exposure assessment.

349 Finally, ozone and other oxidants react with organic species sorbed to surfaces, including human skin. ${ }^{86-88,}$

35092,93 The reactivity of SVOCs with oxidizing agents varies greatly and thus indoor chemistry may not be 351 relevant for all applications. ${ }^{94}$ For chemical reactions in the gas phase to affect indoor environments, their 
reaction rate has to be shorter than or close to the air exchange rate. ${ }^{75}$ This time constraint does not apply

353 to reactions on indoor surfaces, making them particularly important. ${ }^{75}$ Indoor chemistry modeling 354 approaches are available but still limited regarding their parametrization, especially for SVOCs, and 355 represent a focus of ongoing research. ${ }^{75,88,90}$

\subsubsection{Exposure}

Based on the equations discussed in the previous sections, SVOC concentrations in specific indoor compartments can be predicted, and then used to estimate exposure. The following general exposure pathways are considered: Dermal exposure, inhalation exposure and non-dietary ingestion. Dermal exposure can be regarded as a two-step process: Skin-surface lipid uptake refers to the transfer of a chemical to the skin surface, while transdermal uptake describes transfer through the skin into body tissues and blood. For transdermal uptake, the permeability of the skin becomes important. ${ }^{89,95}$ For this 364 framework, we focus on skin-surface lipid uptake.

Direct Exposure can occur via dermal uptake by direct contact with the source, by ingestion of a source and mouthing of the source (source-to-mouth behavior). Indirect Exposure pathways are dermal uptake

367 from the gas phase, airborne particles and via contact with dust, sink surfaces, or clothing, inhalation of 368 air (gas phase and airborne particles), ingestion of dust, mouthing of objects that are not the source, 369 including clothing and hand-to-mouth behavior.

371 When the skin is in direct contact with a source (solid or liquid), partitioning of SVOCs between the source 372 and the skin-surface lipids takes place (Eq. 12a in the SI). A simple approach to describe the flux from a 373 solid source surface to the skin surface has been used by the U.S. Consumer Product Safety Commission 374 (U.S. CPSC). It incorporates a migration rate and the skin surface area in contact with the source. ${ }^{96}$ Other 
375 approaches assume that the transferred amount of SVOC depends on the SVOC concentration in the 376 source and relate this property to either a thin layer of SVOC present on the source surface or to the 377 diffusive flux of SVOC from within the source to its exterior. ${ }^{97,}{ }^{98}$ A summary of these equations can be 378 found in Huang et al. ${ }^{23}$ However, none of the mentioned approaches appears to be fully developed and 379 further research has to be conducted for a mechanistically consistent model. For the transfer from liquid 380 sources applied to the skin, a simplified form of the approaches used by Wormuth et al. ${ }^{56}$ and Giovanoulis 381 et al. ${ }^{99}$ can be used.

Following the transfer from the source to the skin-surface lipids, the subsequent transdermal uptake from the skin-surface lipids to the dermal capillaries can be described by multiplying the concentration of SVOCs on the skin surface $C_{\text {ssl }}$ with the dermal permeability coefficient $k_{\mathrm{p}_{-} \text {ss. }}{ }^{21,89}$

The transdermal exposure rate $E x_{\text {trans }}$ from SVOCs present in the gas phase to dermal capillaries depends on the SVOC gas phase concentration $C_{g}$, the overall transdermal permeability coefficient $k_{p_{-} g}$ and the exposed body surface area $A_{\text {exp }}$ (Eq. $13 \mathrm{a}$ in the $\left.\mathrm{SI}\right) .{ }^{95} k_{p_{-} g}$ can be calculated based on a resistor-in-series model that takes into account the mass transfer coefficient from the bulk gas phase through the boundary layer of the skin as well as the compound-specific permeability coefficient through the stratum corneum/viable epidermis composite. ${ }^{21,89,95}$ The model has been extended under dynamic conditions by Gong et al. ${ }^{100}$ and further by Morrison et al. ${ }^{50}$

Dermal absorption of SVOCs associated with airborne particles is expected to be much smaller than dermal 394 absorption from the gas phase because particles diffuse much more slowly than gases. ${ }^{95} \mathrm{~A}$ specific model for dermal uptake of SVOCs associated with airborne particles or dust is given in Equation 13b in the SI. source. Equation $13 \mathrm{c}$ in the SI describes the dermal uptake of SVOCs from sink surfaces. The equation 
399 deposited on the sink surface is transferred when touched. ${ }^{101}$ Both parameters however are not well400 established for SVOCs and further research is necessary. ${ }^{23}$ Dermal uptake from contact with clothing 401 materials can be modeled using Equation 13d in the SI. Critical parameters are the SVOC concentration in 402 skin-surface lipids, which depends on the partitioning between clothing and skin-surface lipids and the 403 SVOC concentration in the clothing material, the transdermal permeability coefficient from the skin404 surface lipids into dermal capillaries and the exposed skin surface area. The model can be varied in 405 complexity as described in Morrison et al. ${ }^{49}$ and Cao et al. ${ }^{84}$ However, because Equation $13 \mathrm{~d}$ assumes 406 equilibrium between the skin-surface lipids and the clothing, it describes a worst-case scenario. In many 407 cases, the duration of contact between clothing and skin is shorter than the time needed to reach 408 equilibrium. ${ }^{26}$

409 Inhalation

410 For inhalation exposure, the inhalation rate $I R_{\text {inh }}$ and the total SVOC concentration in the air are critical 411 parameters (Eq. 14 in the SI). ${ }^{21} I R_{\text {inh }}$ is well documented by the U.S. EPA Exposure Factors Handbook for 412 different age ranges, activity levels and genders. ${ }^{102}$ However, larger particles may be deposited along the 413 way and some fraction may be exhaled again or swallowed. ${ }^{21,23,103}$ Thus intake and bioavailability fractions 414 should be taken into account.

415 Ingestion and Mouthing of a Source

416 Non-dietary ingestion of a source (e.g., shampoo, lotion) and mouthing of a source is particularly relevant 417 for young children (Eqs. $12 \mathrm{~b}$ and $12 \mathrm{c}$ in the SI). Studies have also been conducted to explore the solubility 418 and leachability of chemicals in saliva from various children's products. ${ }^{96,104}$

419 Ingestion of Dust, Hand-to-mouth and Object-to-mouth Exposure

420 Ingestion of dust can occur via hand-to-mouth and object-to-mouth contact, especially for young 421 children. ${ }^{105}$ Exposure via dust ingestion can be estimated using the dust intake rate $I R_{\text {dust }}$ and the weight 
422 fraction of SVOCS associated with the dust (Eq. 15a in the SI). ${ }^{21,23}$ As with $I R_{\text {inh, }}$ the U.S. EPA Exposure

423 Factors Handbook provides values for $I R_{\text {dust }}{ }^{21}$ SVOC bioaccessibility in dust has to be taken into account as

424 well, as discussed in Raffy et al. $2018^{106}$.

425 For calculation of exposure to SVOCs present on the skin (but not adhered to dust) via hand-to-mouth and 426 object-to-mouth (e.g. clothing) contact, the frequency of contact events per hour and the amount 427 transferred to the mouth at each contact have to be taken into account. ${ }^{21,23}$ Also, the amount present on 428 the hand or object must be known along with the fraction of the surface area in contact with the mouth. ${ }^{21}$,

$429{ }^{23}$ Huang et al. ${ }^{23}$ propose a removal efficiency relationship that has also been used in similar form by Isaacs 430 et al. ${ }^{101}$, who obtained their relationship by using SHEDS-MM to fit available data.

\section{$432 \quad 3.3$ Uncertainty}

433 Uncertainty is introduced in the equations at any point where a parameter is being estimated. Additionally,

434 measured parameters are restricted to the test conditions with inherent errors. Here, we plan to include

435 uncertainty as probability distributions if available. The material-phase concentration $C_{0}$, the octanol/air 436 partition coefficient $K_{\mathrm{oa}}$ and the saturation vapor pressure $p_{\mathrm{s}}$ are critical parameters for modeling SVOC 437 emission, transport and subsequent exposure, because they are commonly used to estimate partition 438 coefficients. ${ }^{26,34,43,107}$ Dust and particle properties such as the settled dust density $\rho_{\text {dust }}$, the particle density

$439 \rho_{\text {part }}$ and the organic content of dust $\left(f_{\text {om_dust }}\right)$ and particles $\left(f_{\text {om_part }}\right)$ are also necessary to describe SVOC 440 distribution between different phases indoors. ${ }^{107,108}$ Dust and particle properties vary greatly among 441 different indoor environments (e.g., due to smoking, pets, or occupant habits) thus modeling cannot 442 account for individual settings but has to rely on averages based on measurements. Salthammer and 443 Schripp ${ }^{108}$ reviewed the results of several dust sampling campaigns, with some of the data listed in the SI 444 for reference. Other frequently used values can be found in Weschler and Nazaroff ${ }^{35}$. The uncertainty 
445 associated with any of these parameters propagates further when using them to obtain other modeling

446 parameters.

$447 \quad C_{0}$ can be measured relatively easily with chemical extraction methods and GC-MS analysis. ${ }^{109,110}$ Suspect-

448 screening analysis and non-targeted analysis of chemicals in products can further expand our knowledge

449 of product composition. ${ }^{111}$ Databases such as the U.S. EPA's Chemical and Products Database (CPDat),

450 which is part of the CompTox Chemistry Dashboard, provide additional information on product

451 composition and reference values that can be used for modeling. ${ }^{112,113}$

$452 p_{\mathrm{s}}$ and $K_{\mathrm{oa}}$, on the other hand, are often insufficiently known for SVOCs, particularly at room temperature 453 and for less volatile compounds, which makes calculating partition coefficients challenging. ${ }^{108}$ Salthammer 454 and Schripp ${ }^{108}$ reviewed the available literature and reported that values of $p_{\mathrm{s}}$ for one SVOC can span 455 several orders of magnitude based on different measurement techniques. They estimated that the 456 uncertainty for a given $p_{\mathrm{s}}$ is given as $p_{\mathrm{s}} \pm 0.95 \cdot p_{\mathrm{s}}$, following a normal distribution. ${ }^{108}$

457 Determining $K_{\text {oa }}$ experimentally requires substantial effort, thus most $K_{\text {oa }}$ values found in the literature 458 have been derived from the air/water partition coefficient $K_{\mathrm{aw}}$, the octanol/water partition coefficient $K_{\mathrm{ow}}$ 459 and/or Henry's law constant $H .{ }^{108,114,115}$ The uncertainty of $K_{\text {oa }}$ can be calculated as the combined 460 uncertainty of the parameters used to obtain $K_{\text {oa. }}$. For example, if $K_{\text {oa }}=K_{\text {ow }} R T / H$ is used, the uncertainty of $461 K_{\text {oa }}$ is the combined uncertainty of $K_{\text {ow }}$ and $H \cdot{ }^{108}$ Alternatively, $K_{\text {oa }}$ can be determined from linear free 462 energy relationships as described by Schwarzenbach et al. (2017). ${ }^{116}$ Numerous algorithms and 463 quantitative-structure-property relationship (QSPR) approaches have been developed for the prediction 464 of chemical properties. ${ }^{117}$ These are available via software tools like SPARC, EPI Suite and LSER to estimate $465 K_{\text {oa }}$ and $p_{\mathrm{s} .}{ }^{108,118}$ However, the results might differ depending on the selected algorithm and, in case of 466 QSPR approaches, on the quality of the input data. Moreover, associated uncertainties are difficult to 467 quantify. ${ }^{114}$ 
469 arise from the sigmoidal shape of the equation predicting the particle fraction, especially for compounds

470 of medium volatility $\left(10^{-6} \mathrm{~Pa}<p_{\mathrm{s}}<10^{-2} \mathrm{~Pa}\right)$. Small changes in $p_{\mathrm{s}}, K_{\text {ow }}$ and $H$ (and thus $\left.K_{\text {oa }}\right)$ result in large

471 differences in the concentration ratio between gas and particle phase. ${ }^{108,}{ }^{114}$ In those cases, it is not

472 possible to tell if an SVOC is predominantly in the gas or in the particle phase. Generally, the range of error

473 of both experimentally derived and calculated values for $K_{\mathrm{p}}$ is within one order of magnitude. ${ }^{118}$

$474 y_{0}$ is a critical parameter to describe emission, and can be measured directly. ${ }^{39,}{ }^{44}$ Furthermore, $y_{0}$ can also

475 be derived from correlations with $C_{0}$ for certain SVOCs ${ }^{43}$, 46 . Similarly, regressions for different classes of

476 SVOCs partitioning to certain types of sink materials have been established to estimate $K_{\mathrm{s}} .{ }^{33,81,119}$ However,

477 these correlations also depend on $p_{\mathrm{s}}$ and have similar challenges as discussed above.

478 When calculating distributions, Monte-Carlo simulations are helpful to quantify how uncertainties

479 propagate to derived parameters. Wei et al. ${ }^{107}$ reviewed published data for $K_{\mathrm{p}}$ and $K_{\text {dust }}$ and described the 480 distributions of $\log _{10} K_{\mathrm{p}}$ and $\log _{10} K_{\text {dust }}$ for 72 SVOCS that can be used as references for Monte-Carlo 481 simulations. They also developed an empirical linear relationship between $\log _{10} K_{\mathrm{p}}$ and $\log _{10} K_{\text {dust, }}$ which may 482 serve to estimate $K_{\text {dust }}$ based on $K_{\mathrm{p}}$ or vice versa, if no other sources are available. ${ }^{107}$ Additionally, modeling 483 parameters, especially partition coefficients, are influenced by indoor environmental factors, e.g., 484 temperature, humidity, ventilation, size fractions of airborne particles and potential biodegradation of 485 SVOCs. ${ }^{22,42,78,79,120}$ These relationships still require further research, but utilizing parameter distributions 486 as model inputs provide some sense of the uncertainty associated with their estimation.

\subsection{Limitations and Conditions of Use}

As discussed above, the greatest limitation of this framework is the model parametrization. It is often not possible or feasible to measure parameters directly, thus they have to be estimated or obtained from 
491 databases. The implementation of the proposed framework has to include ways to access databases like

492 the U.S. EPA CompTox Chemistry Dashboard and other platforms that contain data derived from HT

493 screening approaches or quantitative-structure-activity relationships (QSARs) which can serve as input for

494 mechanistic models. ${ }^{113,121,122}$ Parameter estimation approaches vary greatly in their accuracy, from 50-

495 year old literature values to data derived from chemistry software, and thus different forms of uncertainty

496 are introduced, which have to be addressed appropriately. The SI supplies information on approaches to

497 estimate important parameters together with ranges of applicability and uncertainty, if available.

498 The modular structure of the framework allows aspects of exposure modeling to chemicals released

499 indoors to be included or excluded. The framework could, for example, be adjusted to include volatile

500 organic compounds (VOCs), or other groups of chemicals, such as per- and polyfluoroalkyl substances

501 (PFAS). Some modules are better understood than others, making it tempting to ignore those that might

502 introduce complexity. However, even if some parts of the framework are not addressed quantitatively,

503 they should be part of the broader discussion of the resulting exposure estimates so that they can be

504 placed in the right context.

505 In addition to chemical-related model parameters, those describing specific exposure scenarios may also

506 be unknown or highly uncertain. Whenever possible, variability has to be taken into account with respect

507 to exposed populations and occupant characteristics, ${ }^{123}$ occupant behaviors, ${ }^{8,}{ }^{124}$ and indoor

508 environmental settings ${ }^{125,126}$. Applying Monte Carlo-based approaches to include parameter distributions

509 and addressing certain "special case" scenarios to identify particularly sensitive populations should be part

510 of the application of the framework. It has been shown, for example, that cooking and cleaning activities

511 greatly enhance the levels of SVOCs in indoor environments compared to background levels. ${ }^{8}$ The

512 possibility of stacked exposures due to certain occupant behaviors and potential consequences for

513 exposed individuals should thus be incorporated in the exposure assessment. 
514 Concepts of bioaccessibility and bioavailability, as discussed for example in Wei et al. $2018^{103}$ for inhalation 515 exposure and in Raffy et al. $2018^{106}$ for dust ingestion, should be considered. SVOC bioaccessibility can 516 span a wide range, depending on the pathway, the specific substance, and many other factors. ${ }^{103,106}$ Thus,

517 when calculating intakes rates based on the models presented in the $\mathrm{SI}$, adjusting factors should be taken 518 into account where available. If they are not available, the resulting intake rates might overestimate actual 519 exposure. For higher complexity modeling purposes, exposure estimates derived with this framework may 520 be combined with mechanistic model describing, for example, the fate of gas and particle phase in the 521 human respiratory tract, possibly followed by the application of physiologically-based pharmacokinetic 522 (PBPK) models to quantitatively predict concentrations in plasma or target tissue. ${ }^{2,103}$

523 Additional uncertainty may be introduced when evaluating SVOC sources that are not in direct contact 524 with the indoor environment, such as those present in the building envelope (e.g. rim joists, vapor 525 barriers). Strongly varying temperatures and infiltration paths into the indoor environment may 526 significantly affect the infiltration rate of SVOCs into the indoor environment.

\section{CONCLUSION}

529 Mechanistic models have been identified as most suitable to address key challenges in exposure modeling.

530 Mechanistically consistent source emission categories are the basis of the proposed framework and allow

531 modelers and users to identify relevant exposure pathways. For modeling these pathways, mechanistic 532 models with different levels of complexity are available and can be applied to derive exposure estimates.

533 Factors influencing the complexity of modeling SVOC emission, transport and exposure in indoor 534 environments include the following:

535 1. Assumption of equilibrium or dynamic conditions; 
2. Consideration of the influence of indoor environmental factors on modeling parameters, especially on partition coefficients (e.g., temperature, humidity, ventilation, size fractions of airborne particles, source loading factor), and respective uncertainties;

3. Consideration of indoor chemistry and SVOC transformation products resulting from oxidation, hydrolysis and other reactions;

4. Consideration of more than one SVOC and the effect of chemical mixtures on partitioning behavior, reactivity and subsequent exposure; and

5. Influence of occupancy (e.g., in terms of surface soiling, dust re-suspension, cleaning habits and other occupant behavior) and occupant characteristics (e.g., age, gender, variability of exposure factors).

Modeling complex scenarios such as indoor environments is a challenging task. We will always have to 547 make concessions, accept uncertainty and even unpredictability, and adapt to new developments. 548 However, this should not stop our progress, but instead, if handled with awareness and transparency, can 549 guide us in our attempts to reasonably reflect the real world in our models.

\section{OUTLOOK}

552 We envision this mechanistic exposure modeling framework to be developed as a community model and

553 to be situated within larger chemical risk assessment frameworks to better understand interdependencies

554 with existing and ongoing research and policies. To achieve this, toxicity data for different endpoints 555 together with toxicokinetic mechanisms have to be combined with exposure estimates, ensuring that the 556 overall goal of rapid and efficient risk ranking and chemical prioritization is being achieved, as generated 557 for example by the U.S. EPA's Toxicity Forecaster (ToxCast), which uses HT screening methods and 558 computational approaches. ${ }^{127-129}$ For example, Shin et al. $2015^{130}$ proposed a strategy to combine exposure 559 estimates based on intake rates with toxicity data derived from ToxCast in vitro bioactivity assays, deriving 
bioactivity quotients (BQ) for $\mathrm{HT}$ risk ranking and prioritization. The approach relies on comprehensive

561 near-field exposure models, as they are presented in our framework. The concept of Intake Fraction (iF)

562 can be used to provide further insight into exposure estimates for screening purposes. ${ }^{131}$

563 The proposed framework can be employed in other contexts. Gwinn et al. $2017^{132}$ proposed a conceptual

564 model for a public health perspective for chemical risk assessment, emphasizing public-health focused risk

565 assessment rather than traditional risk assessment. ${ }^{132}$ Our framework complements this approach,

566 because it incorporates robust mechanistic data and can furthermore inform novel exposure science and

567 biomonitoring approaches that are being used in epidemiology. Additionally, our framework can be

568 integrated with the work of Jolliet et al. $2015^{133}$ and Fantke et al. $2016^{134}$ who developed an approach to

569 integrate near- and far-field exposure assessments with life cycle impact assessment (LCIA), and also for

570 chemical alternatives assessment and risk-based HT purposes.

571 Further validation of the proposed framework, including models and parameters, is needed in an ongoing

572 process. As emphasized before, the modular structure of the framework and the vision to establish it as

573 the basis for an indoor exposure community model are intended to allow rapid and simple optimization of

574 different components, depending on the user's needs and the knowledge available. The iterative

575 implementation process will initially focus on SVOCs, but as work progresses, the source categories can be

576 adjusted, VOC and aerosol emissions can be added, and indoor chemistry can be included. The Community

577 Multiscale Air Quality (CMAQ) model ${ }^{135}$ could serve as an example of how the framework can be

578 developed, with open-source contributions from researchers worldwide and participation of all interested

579 stakeholders. Although the structure of the framework is clear, much remains to be done to fill in the

580 details.

581 Exposure science plays a crucial role in a fully integrated system of chemical risk assessment to inform and

582 prioritize toxicity testing, describe and rank risks, and develop and validate models. ${ }^{6}$ As recognized by the

583 U.S. National Research Council (NRC) in their 2007 report, Toxicity Testing in the 21st Century: A Vision and 
584 a Strategy ${ }^{136}$, exposure science must be considered at every step of any testing and risk assessment 585 strategy ${ }^{6}$. This is reinforced in the NRC report from 2012 Exposure Science in the 21st Century: A Vision and 586 a Strategy ${ }^{137}$. In 2017, Using 21st Century Science to Improve Risk-Related Evaluations ${ }^{138}$ picks up where 587 the previous NRC reports left off and provides strategies for integrating new scientific methods, new ways 588 of data validation, approaches to integrate divergent data streams, approaches to address uncertainties 589 and ways to communicate new approaches to stakeholders.

590 Understanding the health effects of exposures to chemicals has real implications for public health.

591 Currently, chemicals management authorities focus on evaluating risks from exposures to individual or 592 groups of chemicals based on the properties of those chemicals. This approach rarely enables policy 593 makers to link increased risk of public health outcomes to chemical management actions. As a result, 594 chemical managers are challenged to anticipate impacts of chemical use and focus resources on addressing 595 the most pressing concerns. A public health perspective starts with the disease of concern and 596 incorporates multiple data streams to inform preventative policy decisions. The goal is to extend the scope 597 of considerations that support chemical management decisions and advance the tools for integrating this 598 more complex information.

599 Epidemiological studies increasingly report observations of adverse health effects at chemical exposure 600 levels predicted from animal toxicology studies to be safe for humans. Understanding public health risk 601 from environmental chemical exposures is complicated by factors that include population variability and 602 susceptibility, latencies between critical exposures and disease outcomes, and background environmental 603 exposures. To protect public health more effectively, future risk assessments will need to take a more 604 holistic perspective, consider the full range of available data, draw on innovative methods to integrate 605 diverse data streams, and consider health endpoints that better reflect impacts observed in human 606 populations. In concert with current advances in exposure science (e.g., as describe in Thomas et al. 
$\left.6072019^{129}\right)$, the proposed framework will further enable the goal of combining chemical risk and population 608 health perspectives.

609 


\section{APPENDIX: Signatories}

611 List of signatories who support the proposed framework 


\section{Disclaimer}

614 The views expressed in this article are those of the authors and do not necessarily represent the views or 615 policies of any agency.

616

617 Acknowledgements

618 This work was initially funded by the National Toxicology Program, United States Department of Health 619 and Human Services, and we thank Dr. John Bucher for support and guidance. We also acknowledge the 620 Scientific and Technical Center for Building (CSTB) and the University of La Rochelle, both in France, for 621 providing sabbatical support for John Little, which further catalyzed the work, and the Department of 622 Building Science at Tsinghua University for hosting the kick-off workshop.

623

624 Supplementary Information

625 Nomenclature, List of Consensus Points, Mechanistic Modeling Framework to Predict Exposure to SVOCs 626 (Figure S1), Emission and Transport Modeling Equations, Exposure Modeling Equations, Estimation

627 Approaches for Model Parameters, Comparison of $K_{\text {oa }}$ values (Figure S2) 
631

632

633

634

635

636

637

638

639

640

641

642

643

644

645

646

647

648

649

650

651

652

653

654

655

656

657

658

659

660

661

662

663

664

665

666

667

668

669

670

671

672

673

674

675

676

1. Bolinius, D. J.; Sobek, A.; Löf, M. F.; Undeman, E., Evaluating the consumption of chemical products and articles as proxies for diffuse emissions to the environment. Environmental Science: Processes \& Impacts 2018, 20, 1427-1440.

2. Cohen Hubal, E. A.; Wetmore, B. A.; Wambaugh, J. F.; El-Masri, H.; Sobus, J. R.; Bahadori, T., Advancing internal exposure and physiologically-based toxicokinetic modeling for 21st-century risk assessments. J. Expo. Sci. Environ. Epidemiol. 2019, 29, 11-20.

3. Kavlock, R. J.; Bahadori, T.; Barton-Maclaren, T. S.; Gwinn, M. R.; Rasenberg, M.; Thomas, R. S., Accelerating the Pace of Chemical Risk Assessment. Chem. Res. Toxicol. 2018, 31, 287-290.

4. Eichler, C. M. A.; Cohen Hubal, E. A.; Little, J. C., Assessing Human Exposure to Chemicals in Materials, Products and Articles: The International Risk Management Landscape for Phthalates. Environ. Sci. Technol. 2019, Under review.

5. Morrison, G. C.; Carslaw, N.; Waring, M. S., Editorial: A modeling enterprise for chemistry of indoor environments (CIE). Indoor Air 2017, 27, (6), 1033-1038.

6. Sheldon, L. S.; Cohen Hubal, E. A., Exposure as Part of a Systems Approach for Assessing Risk. Environ. Health Perspect. 2009, 117, (8), 1181-1184.

7. Li, D.; Suh, S., Health risks of chemicals in consumer products: A review. Environ. Int. 2019, 123, 580-587.

8. $\quad$ Kristensen, K.; Lunderberg, D. M.; Liu, Y.; Misztal, P. K.; Tian, Y.; Arata, C.; Nazaroff, W. W.; Goldstein, A. H., Sources and dynamics of semivolatile organic compounds in a single - family residence in northern California. Indoor Air 2019, 29, 645-655.

9. Lucattini, L.; Poma, G.; Covaci, A.; de Boer, J.; Lamoree, M. H.; Leonards, P. E. G., A review of semi-volatile organic compounds (SVOCs) in the indoor environment: occurrence in consumer products, indoor air and dust. Chemosphere 2018, 201, 466-482.

10. Guo, Y.; Kannan, K., A Survey of Phthalates and Parabens in Personal Care Products from the United States and Its Implications for Human Exposure. Environ. Sci. Technol. 2013, 47, (24), 1444214449.

11. Nicolas, C. I.; Mansouri, K.; Phillips, K. A.; Grulke, C. M.; Richard, A. M.; Williams, A. J.;

Rabinowitz, J.; Isaacs, K. K.; Yau, A.; Wambaugh, J. F., Rapid experimental measurements of physicochemical properties to inform models and testing. Sci. Total Environ. 2018, 636, 901-909.

12. Phillips, K. A.; Wambaugh, J. F.; Grulke, C. M.; Dionisio, K. L.; Isaacs, K. K., High-throughput screening of chemicals as functional substitutes using structure-based classification models. Green Chem. 2017, 19, (4), 1063-1074

13. Moreau, M.; Leonard, J.; Phillips, K. A.; Campbell, J.; Pendse, S. N.; Nicolas, C.; Phillips, M.; Yoon, M.; Tan, Y.-M.; Smith, S.; Pudukodu, H.; Isaacs, K.; Clewell, H., Using exposure prediction tools to link exposure and dosimetry for risk-based decisions: A case study with phthalates. Chemosphere 2017, 184, $1194-1201$.

14. Isaacs, K. K.; Wambaugh, J. F., Advances in EPA's Rapid Exposure and Dosimetry Project. In Interagency Alternatives Assessment Webinar ed.; US EPA: 2016.

15. Wambaugh, J. F.; Wang, A.; Dionisio, K. L.; Frame, A.; Egeghy, P.; Judson, R. S.; Woodrow Setzer, R., High Throughput Heuristics for Prioritizing Human Exposure to Environmental Chemicals. Environ. Sci. Technol. 2014, 48, 12760-12767.

16. Russo, D. P.; Strickland, J.; Karmaus, A. L.; Wang, W.; Shende, S.; Hartung, T.; Aleksunes, L. M.; Zhu, H., Nonanimal Models for Acute Toxicity Evaluations: Applying Data-Driven Profiling and ReadAcross. Environ. Health Perspect. 2019, 127, (4), 047001-1-047001-14.

17. USEPA, High-Throughput Exposure Forecasting. In Development, O. o. R. a., Ed. US

Environmental Protection Agency: 2016. 
18. Wambaugh, J. F.; Ring, C. L.; Isaacs, K. K.; Phillips, K. A.; Egeghy, P. P.; Woodrow Setzer, R., Predicting Exposure Pathways Allows Risk-Based Prioritization. In The Toxicology Forum 42nd Annual Winter Meeting, Washington, DC, 2018. 19. Koivisto, A. J.; Kling, K. A.; Hänninen, O.; Jayjock, M.; Löndahl, J.; Wierzbicka, A.; Fonseca, A. S.; Uhrbrand, K.; Boor, B. E.; Jiménez, A. S.; Hämeri, K.; Dal Maso, M.; Arnold, S. F.; Jensen, K. A.; Viana, M.; Morawska, L.; Hussein, T., Source specific exposure and risk assessment for indoor aerosols. Sci. Total Environ. 2019, 668, 13-24.

20. Wood, M. D.; Plourde, K.; Larkin, S.; Egeghy, P. P.; Williams, A. J.; Zemba, V.; Linkov, I.; Vallero, D. A., Advances on a Decision Analytic Approach to Exposure-Based Chemical Prioritization. Risk Anal. 2018, Online version.

21. Salthammer, T.; Zhang, Y.; Mo, J.; Koch, H. M.; Weschler, C. J., Assessing human exposure to organic pollutants in the indoor environment. Angewandte Chemie International Edition 2018. 22. Liang, Y.; Bi, C.; Wang, X.; Xu, Y., A general mechanistic model for predicting the fate and transport of phthalates in indoor environments. Indoor Air 2019, 29, 55-69.

23. Huang, L.; Ernstoff, A. S.; Fantke, P.; Csiszar, S. A.; Jolliet, O., A review of models for near-field exposure pathways of chemicals in consumer products. Sci. Total Environ. 2017, 574, 1182-1208.

24. WHO Indoor air quality: organic pollutants; World Health Organization: Copenhagen, NL, 1989.

25. ISO, 16000-6 Indoor air -- Part 6: Determination of volatile organic compounds in indoor and test chamber air by active sampling on Tenax TA sorbent, thermal desorption and gas chromatography using MS or MS-FID. In 13.040.20 - Ambient atmospheres, International Organization for Standardization: 2011.

26. Weschler, C. J.; Nazaroff, W. W., Semivolatile organic compounds in indoor environments. Atmos. Environ. 2008, 42, (40), 9018-9040.

27. van t'Erve, T. J.; Rosen, E. M.; Barrett, E. S.; Nguyen, R. H. N.; Sathyanarayana, S.; Milne, G. L.; Calafat, A. M.; Swan, S. H.; Ferguson, K. K., Phthalates and phthalate alternatives have diverse associations with oxidative stress and inflammation in pregnant women. Environ. Sci. Technol. 2019, 53, 3258-3267.

28. Liu, W.; Huang, C.; Li, B. Z.; Zhao, Z.; Xu, Y.; Deng, Q.; Zhang, X.; Qian, H.; Sun, Y.; Qu, F.; Wang, L.; Lin, J. Z.; Lu, C.; Wang, H.; Wang, J.; Cai, J.; Zhang, J.; Sun, C. J.; Mo, J.; Weschler, L. B.; Norbäck, D.; Sundell, J.; Zhang, Y., Household renovation before and during pregnancy in relation to preterm birth and low birthweight in China. Indoor Air 2019, 29, 202-214.

29. Bi, C.; Maestre, J. P.; Li, H.; Zhang, G.; Givehchi, R.; Mahdavi, A.; Kinney, K. A.; Siegel, J.; Horner, S. D.; Xu, Y., Phthalates and organophosphates in settled dust and HVAC filter dust of U.S. low-income homes: Association with season, building characteristics, and childhood asthma. Environ. Int. 2018, 121, 916-930.

30. Lu, X.; Xu, X.; Lin, Y.; Zhang, Y.; Huo, X., Phthalate exposure as a risk factor for hypertension. Environmental Science and Pollution Research 2018, 25, 20550-20561.

31. Little, J. C.; Weschler, C. J.; Nazaroff, W. W.; Liu, Z.; Cohen Hubal, E. A., Rapid Methods to Estimate Potential Exposure to Semivolatile Organic Compounds in the Indoor Environment. Environ. Sci. Technol. 2012, 46, (20), 11171-11178.

32. Melymuk, L.; Bohlin-Nizzetto, P.; Vojta, S.; Krátká, M.; Kukucka, P.; Audy, O.; Pribylová, P.; Klánová, J., Distribution of legacy and emerging semivolatile organic compounds in five indoor matrices in a residential environment. Chemosphere 2016, 153, 179-186.

33. Xu, Y.; Little, J. C., Predicting emissions of SVOCs from polymeric materials and their interaction with airborne particles. Environ. Sci. Technol. 2006, 40, (2), 456-461.

34. Weschler, C. J.; Salthammer, T.; Fromme, H., Partitioning of phthalates among the gas phase, airborne particles and settled dust in indoor environments. Atmos. Environ. 2008, 42, 1449-1460. 35. Weschler, C. J.; Nazaroff, W. W., SVOC partitioning between the gas phase and settled dust indoors. Atmos. Environ. 2010, 44, (30), 3609-3620. 
36. Liu, C.; Zhao, B.; Zhang, Y., The influence of aerosol dynamics on indoor exposure to airborne DEHP. Atmos. Environ. 2010, 44, (16), 1952-1959.

37. Clausen, P. A.; Liu, Z.; Kofoed-Sørensen, V.; Little, J. C.; Wolkoff, P., Influence of Air Flow Rate on Emission of DEHP from Vinyl Flooring: Measurements and CFD Simulation. Atmos. Environ. 2010, 44, 2760-2766.

38. Clausen, P. A.; Liu, Z.; Kofoed-Sørensen, V.; Little, J. C.; Wolkoff, P., The Influence of Temperature on the Emission of $\mathrm{Di}(2$ ethylhexyl)phthalate (DEHP) from PVC Flooring in the Emission Cell FLEC. Environ. Sci. Technol. 2012, 46, (2), 909-915.

39. Wu, Y.; Xie, M.; Cox, S. S.; Marr, L. C.; Little, J. C., Simple method to measure the gas-phase SVOC concentration adjacent to a material surface. Indoor Air 2015, 26, (6), 903-912.

40. Wu, Y.; Eichler, C. M. A.; Chen, S.; Little, J. C., Simple Method To Measure the Vapor Pressure of Phthalates and Their Alternatives. Environ. Sci. Technol. 2016, 50, 10082-10088.

41. Wu, Y.; Eichler, C. M. A.; Leng, W.; Cox, S. S.; Marr, L. C.; Little, J. C., Adsorption of Phthalates on Impervious Indoor Surfaces. Environ. Sci. Technol. 2017, 51, (5), 2907-2913.

42. Wu, Y.; Eichler, C. M. A.; Cao, J.; Benning, J. L.; Olson, A.; Chen, S.; Liu, C.; Vejerano, E. P.; Marr, L. C.; Little, J. C., Particle/gas partitioning of phthalates to organic and inorganic airborne particles in the indoor environment. Environ. Sci. Technol. 2018, 52, (6), 3583-3590.

43. Eichler, C. M. A.; Wu, Y.; Cao, J.; Shi, S.; Little, J. C., Equilibrium relationship between SVOCs in PVC products and the air in contact with the product. Environ. Sci. Technol. 2018, 52, (5), 2918-2925. 44. Liang, Y.; $\mathrm{Xu}, \mathrm{Y}$., Improved method for measuring and characterizing phthalate emissions from building materials and its application to exposure assessment. Environ. Sci. Technol. 2014, 48, (8), 44754484 .

45. Liang, Y.; Xu, Y., Emission of Phthalates and Phthalate Alternatives from Vinyl Flooring and Crib Mattress Covers: The Influence of Temperature. Environ. Sci. Technol. 2014, 48, (24), 14228-14237.

46. Liang, Y.; Liu, X.; Allen, M. R., Measurements of Parameters Controlling the Emissions of Organophosphate Flame Retardants in Indoor Environments. Environ. Sci. Technol. 2018, 52, (10), 58215829.

47. Cao, J.; Weschler, C. J.; Luo, J.; Zhang, Y., Cm-History Method, a Novel Approach to Simultaneously Measure Source and Sink Parameters Important for Estimating Indoor Exposures to Phthalates. Environ. Sci. Technol. 2016, 50, (2), 825-834.

48. Morrison, G. C.; Weschler, C. J.; Bekö, G.; Koch, H. M.; Salthammer, T.; Schripp, T.; Toftum, J.; Clausen, G., Role of clothing in both accelerating and impeding dermal absorption of airborne SVOCs. J. Expo. Sci. Environ. Epidemiol. 2016, 26, 113-118.

49. Morrison, G. C.; Weschler, C. J.; Bekö, G., Dermal uptake of phthalates from clothing: Comparison of model to human participant results. Indoor Air 2017, 27, (3), 642-649.

50. Morrison, G. C.; Weschler, C. J.; Bekö, G., Dermal uptake directly from air under transient conditions: advances in modeling and comparisons with experimental results for human subjects. Indoor Air 2016, 26, (6), 913-924.

51. Weschler, C. J.; Bekö, G.; Koch, H. M.; Salthammer, T.; Schripp, T.; Toftum, J.; Clausen, G., Transdermal uptake of diethyl phthalate and di(n-butyl) phthalate directly from air: Experimental verification. Environ. Health Perspect. 2015, 123, (10), 928-934.

52. Weschler, C. J.; Nazaroff, W. W., Growth of organic films on indoor surfaces. Indoor Air 2017, 27, (6), 1101-1112.

53. Eichler, C. M. A.; Cao, J.; Isaacman-VanWertz, G.; Little, J. C., Modeling the Formation and Growth of Organic Films on Indoor Surfaces. Indoor Air 2019, 29, 17-29.

54. Mao, Y.-F.; Li, Z.; Zhang, Y.; He, Y.-L.; Tao, W.-Q., A review of mass-transfer models and mechanistic studies of semi-volatile organic compounds in indoor environments. Indoor and Built Environment 2017, 0, (0), 1-15. 
55. Serrano, S. E.; Braun, J.; Trasande, L.; Dills, R.; Sathyanarayana, S., Phthalates and diet: a review of the food monitoring and epidemiology data. Environmental Health: A Global Access Science Source 2014, 13, 43.

56. Wormuth, M.; Scheringer, M.; Vollenweider, M.; Hungerbühler, K., What are the sources of exposure to eight frequently used phthalic acid esters in Europeans? Risk Anal. 2006, 26, (3), 803-824. 57. Phthalate Esters. Springer-Verlag: Berlin, Heidelberg, 2003.

58. Li, L.; Westgate, J. N.; Hughes, L.; Zhang, X.; Givehchi, B.; Toose, L.; Armitage, J. M.; Wania, F.; Egeghy, P.; Arnot, J. A., A Model for Risk-Based Screening and Prioritization of Human Exposure to Chemicals from Near-Field Sources. Environ. Sci. Technol. 2018, 52, (24), 14235-14244.

59. Wei, W.; Ramalho, O.; Malingre, L.; Sivanantham, S.; Little, J. C.; Mandin, C., Machine learning and statistical models for predicting indoor air quality. Indoor Air 2019, Just accepted.

60. Licina, D.; Morrison, G. C.; Bekö, G.; Weschler, C. J.; Nazaroff, W. W., Clothing-Mediated Exposures to Chemicals and Particles. Environ. Sci. Technol. 2019, Just accepted, XXX-XXX.

61. Bekö, G.; Morrison, G.; Weschler, C. J.; Koch, H. M.; Pälmke, C.; Salthammer, T.; Schripp, T.; Eftekhari, A.; Toftum, J.; Clausen, G., Dermal uptake of nicotine from air and clothing: Experimental verification. Indoor Air 2018, 28, 247-257.

62. Cao, J.; Mo, J.; Sun, Z.; Zhang, Y., Indoor particle age, a new concept for improving the accuracy of estimating indoor airborne SVOC concentrations, and applications. Build. Environ. 2018, 136, 88-97. 63. Xu, Y.; Liu, Z.; Park, J.; Clausen, P. A.; Benning, J. L.; Little, J. C., Measuring and Predicting the Emission Rate of Phthalate Plasticizer from Vinyl Flooring in a Specially-Designed Chamber. Environ. Sci. Technol. 2012, 46, (22), 12534-12541.

64. Pei, J.; Yin, Y.; Cao, J.; Sun, Y.; Liu, J.; Zhang, Y., Time dependence of characteristic parameter for semi-volatile organic compounds (SVOCs) emitted from indoor materials. Build. Environ. 2017, 125, 339347.

65. Wang, P.; Wang, S. L.; Fan, C. Q., Atmospheric distribution of particulate- and gas-phase phthalic esters (PAEs) in a Metropolitan City, Nanjing, East China. Chemosphere 2008, 72, (10), 1567-1572.

66. Teil, M. J.; Blanchard, M.; Chevreuil, M., Atmospheric fate of phthalate esters in an urban area (Paris-France). Sci. Total Environ. 2006, 354, (2-3), 212-223.

67. Rudel, R. A.; Perovich, L. J., Endocrine disrupting chemicals in indoor and outdoor air. Atmos. Environ. 2009, 43, 170-181.

68. Hoffman, K.; Hammel, S. C.; Phillips, A. L.; Lorenzo, A. M.; Chen, A.; Calafat, A. M.; Ye, X.; Webster, T. F.; Stapleton, H. M., Biomarkers of exposure to SVOCs in children and their demographic associations: The TESIE Study. Environ. Int. 2018, 119, 26-36.

69. Li, L.; Arnot, J. A.; Wania, F., How are Humans Exposed to Organic Chemicals Released to Indoor Air? Environ. Sci. Technol. 2019, Online Article.

70. Seifert, B.; Ullrich, D., Methodologies for evaluating sources of volatile organic chemicals (VOC) in homes. Atmos. Environ. 1987, 21, (2), 395-404.

71. Liu, X.; Guo, Z.; Krebs, K. A.; Greenwell, D. J.; Roache, N. F.; Stinson, R. A.; Nardin, J. A.; Pope, R. H., Laboratory Study of PCB Transport from Primary Sources to Settled Dust. Chemosphere 2016, 149, 6269.

72. $\mathrm{Bi}, \mathrm{C} . ; \mathrm{Li}, \mathrm{H} . ; \mathrm{Xu}, \mathrm{Y}$., Transfer of Phthalates and Their Alternatives from Polyvinyl Chloride Flooring and Crib Mattress Cover into Settled Dust. In preparation.

73. Pelletier, M.; Bonvallot, N.; Ramalho, O.; Blanchard, O.; Mercier, F.; Mandin, C.; Le Bot, B.; Glorennec, P., Dermal absorption of semivolatile organic compounds from the gas phase: Sensitivity of exposure assessment by steady state modeling to key parameters. Environ. Int. 2017, 102, 106-113. 74. Garrido, J. A.; Parthasarathy, S.; Moschet, C.; Young, T. M.; McKone, T. E.; Bennett, D. H., Exposure Assessment For Air-To-Skin Uptake of Semivolatile Organic Compounds (SVOCs) Indoors. Environ. Sci. Technol. 2019, 53, (3), 1608-1616.

75. Weschler, C. J.; Carslaw, N., Indoor Chemistry. Environ. Sci. Technol. 2018, 52, (5), 2419-2428. 
76. Clausen, P. A.; Hansen, V.; Gunnarsen, L.; Afshari, P.; Wolkoff, P., Emission of Di-2-ethylhexyl

Phthalate from PVC Flooring into Air and Uptake in Dust: Emission and Sorption Experiments in FLEC and CLIMPAQ. Environ. Sci. Technol. 2004, 38, (9), 2531-2537.

77. Schripp, T.; Fauck, C.; Salthammer, T., Chamber studies on mass-transfer of di(2ethylhexyl)phthalate (DEHP) and di-n-butylphthalate (DnBP) from emission sources into house dust. Atmos. Environ. 2010, 44, (24), 2840-2845.

78. Bope, A.; Haines, S. R.; Hegarty, B.; Weschler, C. J.; Peccia, J.; Dannemiller, K. C., Degradation of phthalate esters in floor dust at elevated relative humidity. Environmental Science Processes \& Impacts 2019.

79. Wei, W.; Mandin, C.; Ramalho, O., Influence of indoor environmental factors on mass transfer parameters and concentrations of semi-volatile organic compounds. Chemosphere 2018, 195, 223-235.

80. $\mathrm{Bi}, \mathrm{C} . ;$ Liang, Y.; $\mathrm{Xu}, \mathrm{Y}$., Fate and transport of phthalates in indoor environments and the influence of temperature: A case study in a test house. Environ. Sci. Technol. 2015, 49, (16), 9674-9681.

81. Liang, Y.; Liu, X.; Allen, M. R., Measuring and modeling surface sorption dynamics of organophosphate flame retardants on impervious surfaces. Chemosphere 2018, 193, (754-762), 754. 82. Morrison, G. C.; Li, H.; Mishra, S.; Buechlein, M., Airborne phthalate partitioning to cotton clothing. Atmos. Environ. 2015, 115, 149-152.

83. Morrison, G.; Andersen, H. V.; Gunnarsen, L.; Voral, D.; Uhde, E.; Kolarik, B., Partitioning of PCBs from air to clothing materials in a Danish apartment. Indoor Air 2018, 28, (1), 188-197.

84. Cao, J.; Zhang, X.; Zhang, Y., Predicting dermal exposure to gas-phase semi-volatile organic compounds (SVOCs): an improved description of SVOC mass transfer between clothing and skin surface lipids. Environ. Sci. Technol. 2018, 52, 4676-4683.

85. Weschler, C. J., Chemistry in indoor environments: 20 years of research. Indoor Air 2011, 21, 205218.

86. Wang, C.; Waring, M. S., Secondary organic aerosol formation initiated from reactions betweenozone and surface-sorbed squalene. Atmos. Environ. 2014, 84, 222-229.

87. Weschler, C. J., Roles of the human occupant in indoor chemistry. Indoor Air 2016, 26, 6-24.

88. Shiraiwa, M.; Carslaw, N.; Tobias, D. J.; Waring, M. S.; Rim, D.; Morrison, G.; Lakey, P. S. J.; Kruza, M.; von Domaros, M.; Cummings, B. E.; Won, Y., MOdelling Consortium for Chemistry of Indoor Environments (MOCCIE): Integrating chemical processes from molecular to room scales. Environmental Science: Processes \& Impacts 2019, online.

89. Weschler, C. J.; Nazaroff, W. W., SVOC exposure indoors: fresh look at dermal pathways. Indoor Air 2012, 22, (5), 356-377.

90. Liu, X.; Mason, M.; Krebs, K.; Sparks, L., Full-Scale Chamber Investigation and Simulation of Air Freshener Emissions in the Presence of Ozone. Environ. Sci. Technol. 2004, 38, (10), 2802-2812.

91. Mendez, M.; Blond, N.; Blondeau, P.; Schoemaecker, C.; Hauglustaine, D. A., Assessment of the impact of oxidation processes on indoor air pollution using the new time-resolved INCA-Indoor model. Atmos. Environ. 2015, 122, 521-530.

92. Springs, M.; Wells, J. R.; Morrison, G. C., Reaction rates of ozone and terpenes adsorbed to model indoor surfaces. Indoor Air 2011, 21, (4), 319-327.

93. Sleiman, M.; Gundel, L. A.; Pankow, J. F.; Ill, P. J.; Singer, B. C.; Destaillats, H., Formation of carcinogens indoors by surface-mediated reactions of nicotine with nitrous acid, leading to potential thirdhand smoke hazards. PNAS 2010, 107, (15), 6676-6581.

94. Wei, W.; Mandin, C.; Ramalho, O., Reactivity of Semivolatile Organic Compounds with Hydroxyl Radicals, Nitrate Radicals, and Ozone in Indoor Air. Int. J. Chem. Kinet. 2017, 49, (7), 506-521.

95. Weschler, C. J.; Nazaroff, W. W., Dermal Uptake of Organic Vapors Commonly Found in Indoor Air. Environ. Sci. Technol. 2014, 48, 1230-1237.

96. CPSC Review of Exposure Data and Assessments for Select Dialkyl Ortho-Phthalates; U.S. Consumer Product Safety Commission: 2010. 
97. Delmaar, J. E.; Bokkers, B. G. H.; ter Burg, W.; van Engelen, J. G. M., First tier modeling of

873

874

875

876

877

878

879

880

881

882

883

884

885

886

887

888

889

890

891

892

893

894

895

896

897

898

899

900

901

902

903

904

905

906

907

908

909

910

911

912

913

914

915

916

917

918

919

920

consumer dermal exposure to substances in consumerarticles under REACH: A quantitative evaluation of the ECETOC TRAfor consumers tool. Regul. Toxicol. Pharmacol. 2013, 65, 79-86.

98. ECHA, Chapter R.15: Consumer exposure assessment. In European Chemicals Agency: 2016.

99. Giovanoulis, G.; Alves, A.; Papadopoulou, E.; Cousins, A. P.; Schütze, A.; Koch, H. M.; Haug, L. S.;

Covaci, A.; Magnér, J.; Voorspoels, S., Evaluation of exposure to phthalate esters and DINCH in urine and nails from a Norwegian study population. Environmental Research 2016, 151, 80-90.

100. Gong, M.; Zhang, Y.; Weschler, C. J., Predicting dermal absorption of gas-phase chemicals:

transient model development, evaluation, and application. Indoor Air 2014, 24, 292-306.

101. Isaacs, K. K.; Glen, W. G.; Egeghy, P.; Goldsmith, M.-R.; Smith, L.; Vallero, D.; Brooks, R.; Grulke, C. M.; Özkaynak, H., SHEDS-HT: An Integrated Probabilistic Exposure Model for Prioritizing Exposures to Chemicals with Near-Field and Dietary Sources. Environ. Sci. Technol. 2014, 48, (21), 12750-12759.

102. USEPA, Chapter 5 - Soil and Dust Ingestion. In Exposure Factors Handbook, Update of 2011

Edition ed.; US Environmental Protection Agency: 2017.

103. Wei, W.; Bonvallot, N.; Gustafsson, Å.; Raffy, G.; Glorennec, P.; Krais, A.; Ramalho, O.; Le Bot, B.; Mandin, C., Bioaccessibility and bioavailability of environmental semi-volatile organic compounds via inhalation: A review of methods and models. Environ. Int. 2018, 113, 202-213.

104. Ionas, A. C.; Ulevicus, J.; Ballesteros Gómez, A.; Brandsma, S. H.; Leonards, P. E. G.; van de Bor, M.; Covaci, A., Children's exposure to polybrominated diphenyl ethers (PBDEs) through mouthing toys. Environ. Int. 2016, 87, 101-107.

105. von Lindern, I.; Spalinger, S.; Stifelman, M. L.; Stanek, L. W.; Bartrem, C., Estimating Children's Soil/Dust Ingestion Rates through Retrospective Analyses of Blood Lead Biomonitoring from the Bunker Hill Superfund Site in Idaho. Environ. Health Perspect. 2016, 124, (9), 1462-1470.

106. Raffy, G.; Mercier, F.; Glorennec, P.; Mandin, C.; Le Bot, B., Oral bioaccessibility of semi-volatile organic compounds (SVOCs) in settled dust: A review of measurement methods, data and influencing factors. J. Hazard. Mater. 2018, 352, 215-227.

107. Wei, W.; Mandin, C.; Blanchard, O.; Mercier, F.; Pelletier, M.; Le Bot, B.; Glorennec, P.; Ramalho, O., Distributions of the particle/gas and dust/gas partition coefficients for seventy-two semi-volatile organic compounds in indoor environment. Chemosphere 2016, 153, 212-219.

108. Salthammer, T.; Schripp, T., Application of the Junge- and Pankow-equation for estimating indoor gas/particle distribution and exposure to SVOCs. Atmos. Environ. 2015, 106, 467-476.

109. Cox, S. S.; Little, J. C.; Hodgson, A. T., Predicting the Emission Rate of Volatile Organic Compounds from Vinyl Flooring. Environ. Sci. Technol. 2002, 36, (4), 709-714.

110. ASTM, Standard Practice for Determination of Monomeric Plasticizers in Poly (Vinyl Chloride)

(PVC) by Gas Chromatography. In ASTM D7083-16, ASTM International: West Conshohocken, PA, 2016.

111. Phillips, K. A.; Yau, A.; Favela, K. A.; Isaacs, K. K.; McEachran, A.; Grulke, C.; Richard, A. M.;

Williams, A. J.; Sobus, J. R.; Thomas, R. S.; Wambaugh, J. F., Suspect Screening Analysis of Chemicals in Consumer Products. Environ. Sci. Technol. 2018, 52, (3125-3135), 3125.

112. Goldsmith, M.-R.; Grulke, C. M.; Brooks, R. D.; Transue, T. R.; Tan, Y. M.; Frame, A.; Egeghy, P. P.; Edwards, R.; Chang, D. T.; Tornero-Velez, R.; Isaacs, K. K.; Wang, A.; Johnson, J.; Holm, K.; Reich, M.; Mitchell, J.; Vallero, D. A.; Phillips, L.; Phillips, M.; Wambaugh, J. F.; Judson, R. S.; Buckley, T. J.; Dary, C. C., Development of a consumer product ingredient database for chemical exposure screening and prioritization. Food and Chemical Toxicology 2014, 65, 269-279.

113. Dionisio, K. L.; Phillips, K.; Price, P. S.; Grulke, C. M.; Williams, A.; Biryol, D.; Hong, T.; Isaacs, K. K., Data Descriptor: The Chemical and Products Database, a resource for exposure-relevant data on chemicals in consumer products. Scientific Data 2018, 5, (180125), 1-9.

114. Schossler, P.; Schripp, T.; Salthammer, T.; Bahadir, M., Beyond phthalates: Gas phase concentrations and modeled gas/particle distribution of modern plasticizers. Sci. Total Environ. 2011, 409, (19), 4031-4038. 
115. Cousins, I.; Mackay, D., Correlating the physical-chemical properties of phthalate esters using the 'three solubility' approach. Chemosphere 2000, 41, (9), 1389-1399.

116. Schwarzenbach, R. P.; Gschwend, P. M.; Imboden, D. M., Environmental Organic Chemistry. John Wiley \& Sons: Hoboken, NJ, 2017.

117. Boethling, R. S.; Mackay, D., Handbook of Property Estimation Methods for Chemicals:

Environmental and Health Sciences. CRC Press: Boca Raton, FL, 2000.

118. Salthammer, T.; Goss, K.-U., Predicting the Gas/Particle Distribution of SVOCs in the Indoor Environment Using Poly Parameter Linear Free Energy Relationships. Environ. Sci. Technol. 2019, 53, 2491-2499.

119. Xu, Y.; Cohen Hubal, E. A.; Clausen, P. A.; Little, J. C., Predicting Residential Exposure to Phthalate Plasticizer Emitted from Vinyl Flooring: A Mechanistic Analysis. Environ. Sci. Technol. 2009, 43, (7), 23742380.

120. Wei, W.; Ramalho, O.; Mandin, C., A long-term dynamic model for predicting the concentration of semivolatile organic compounds in indoor environments: Application to phthalates. Build. Environ. 2019, 148, 11-19.

121. USEPA Toxicity Estimation Software Tool (TEST). https://www.epa.gov/chemicalresearch/toxicity-estimation-software-tool-test (Jun 30, 2019)

122. Cronin, M. T. D., (Q)SARs to predict environmental toxicities: current status and future needs. Environmental Science: Processes \& Impacts 2017, 19, 213-220.

123. Ring, C. L.; Pearce, R. G.; Woodrow Setzer, R.; Wetmore, B. A.; Wambaugh, J. F., Identifying populations sensitive to environmental chemicals by simulating toxicokinetic variability. Environ. Int. 2017, 106, 105-118.

124. Farmer, D. K.; Vance, M. E.; Abbatt, J. P. D.; Abeleira, A.; Alves, M. R.; Arata, C.; Boedicker, E.; Grassian, V. H.; Hildebrandt Ruiz, L.; Jimenez, J. L.; Kahan, T. F.; Katz, E. F.; Mattila, J. M.; Nazaroff, W. W.; Novoselac, A.; O'Brien, R. E.; Or, V. W.; Patel, S.; Sankhyan, S.; Stevens, P. S.; Tian, Y.; Wade, M.; Wang, C.; Zhou, S.; Zhou, Y., Overview of HOMEChem: House Observations of Microbial and Environmental Chemistry. Environmental Science: Processes \& Impacts 2019, Advance Article.

125. Jayjock, M.; Havics, A. A., Residential inter-zonal ventilation rates for exposure modeling. J. Occup. Env. Hyg. 2018, 15, (5), 376-388.

126. Manuja, A.; Ritchie, J.; Buch, K.; Wu, Y.; Eichler, C. M. A.; Little, J. C.; Marr, L. C., Total surface area in indoor environments. Environmental Science: Processes \& Impacts 2019, Online Article.

127. USEPA Toxicity ForeCaster (ToxCast ${ }^{\mathrm{TM}}$ ) Data. https://www.epa.gov/chemical-research/toxicityforecaster-toxcasttm-data (Jun 20, 2019)

128. USEPA Toxicity Forecasting. https://www.epa.gov/chemical-research/toxicity-forecasting (Jul 2, 2019)

129. Thomas, R. S.; Bahadori, T.; Buckley, T. J.; Cowden, J.; Deisenroth, C.; Dionisio, K. L.; Frithsen, J. B.; Grulke, C. M.; Gwinn, M. R.; J.A., H.; Higuchi, M.; Houck, K. A.; Hughes, M. F.; Hunter, E. S.; Isaacs, K. K.; Judson, R. S.; Knudsen, T. B.; Lambert, J.C.; Linnenbrink, M.; Martin, T. M.; Newton, S. R.; Padilla, S.; Patlewicz, G.; Paul-Friedman, K.; Phillips, K. A.; Richard, A. M.; Sams, A.; Shafer, T. J.; Woodrow Setzer, R.; Shah, I.; Simmons, J. E.; Simmons, S. O.; Singh, A.; Sobus, J. R.; Strynar, M.; Swank, A.; Tornero-Velez, R.; Ulrich, E. M.; Villeneuve, D. L.; Wambaugh, J. F.; Wetmore, B. A.; Williams, A. J., The next generation blueprint of computational toxicology at the U.S. Environmental Protection Agency. Toxicol. Sci. 2019, 169, (2), 317-332.

130. Shin, H.-M.; Ernstoff, A.; Arnot, J. A.; Wetmore, B. A.; Csiszar, S. A.; Fantke, P.; Zhang, X.; McKone, T. E.; Jolliet, O.; Bennett, D. H., Risk-Based High-Throughput Chemical Screening and Prioritization using Exposure Models and in Vitro Bioactivity Assays. Environ. Sci. Technol. 2015, 49, 6760-6771.

131. Shin, H.-M.; McKone, T. E.; Bennett, D. H., Intake Fraction for the Indoor Environment: A Tool for Prioritizing Indoor Chemical Sources. Environ. Sci. Technol. 2012, 46, 10063-10072. 
969 132. Gwinn, M. R.; Axelrad, D. A.; Bahadori, T.; Bussard, D.; Cascio, W. E.; Deener, K.; Dix, D.; Thomas, 970 R. S.; Kavlock, R. J.; Burke, T. A., Chemical Risk Assessment: Traditional vs Public Health Perspectives. Am. 971 J. Public Health 2017, 107, (7), 1032-1039.

972 133. Jolliet, O.; Ernstoff, A. S.; Csiszar, S. A.; Fantke, P., Defining Product Intake Fraction to Quantify 973 and Compare Exposure to Consumer Products. Environ. Sci. Technol. 2015, 49, 8924-8931.

974 134. Fantke, P.; Ernstoff, A. S.; Huang, L.; Csiszar, S. A.; Jolliet, O., Coupled near-field and far-field 975 exposure assessment framework for chemicals in consumer products. Environ. Int. 2016, 94, 508-518.

976 135. Byun, D.; Schere, K. L., Review of the Governing Equations, Computational Algorithms, and Other 977 Components of the Models-3 Community Multiscale Air Quality (CMAQ) Modeling System. Applied 978 Mechanics Reviews 2006, 59, (2), 51-77.

979 136. NRC Toxicity Testing in the 21st Century: A Vision and a Strategy; Washington, DC, 2007.

980 137. NRC Exposure Science in the 21st Century: A Vision and a Strategy; Washington, DC, 2012.

981 138. NASEM Using 21st Century Science to Improve Risk-Related Evaluations; Washington, DC, 2017.

982 
Supplementary Information for

Assessing Human Exposure to Chemicals in Materials, Products and Articles:

\section{A Modular Mechanistic Framework}

Table of Contents:

1) Nomenclature

2) List of Consensus Points

3) Mechanistic Modeling Framework to Predict Exposure to SVOCs

4) Emission and Transport Modeling Equations

5) Exposure Modeling Equations

6) Estimation Approaches for Model Parameters

7) Decision Tree 


\section{1) Nomenclature}

\begin{tabular}{|c|c|}
\hline$A_{\text {contact }}$ & Contact area between skin and sink surface $\left(\mathrm{m}^{2}\right)$ \\
\hline$A_{\text {exp }}$ & Exposed body surface area $\left(\mathrm{m}^{2}\right)$ \\
\hline$A_{\text {mouthing }}$ & Mouthed object surface area $\left(\mathrm{m}^{2}\right)$ \\
\hline$A_{s}$ & Surface area of sink (non-source) surfaces $\left(\mathrm{m}^{2}\right)$ \\
\hline$A_{S S}$ & Surface area of source surfaces $\left(\mathrm{m}^{2}\right)$ \\
\hline $\mathrm{ACH}$ & Air change rate; $A C H=Q / V(1 / \mathrm{h})$ \\
\hline$A R_{\text {source }}$ & Application rate of source $(\mu \mathrm{g} / \mathrm{h})$ \\
\hline$b w$ & Body weight (kg) \\
\hline$C_{0}$ & Material-phase SVOC concentration $\left(\mu \mathrm{g} / \mathrm{m}^{3}\right)$ \\
\hline$C_{\mathrm{a}, \mathrm{sat}}$ & Saturation concentration in air $\left(\mu \mathrm{g} / \mathrm{m}^{3}\right)$ \\
\hline$C_{m}$ & SVOC concentration in clothing material $\left(\mu \mathrm{g} / \mathrm{m}^{3}\right)$ \\
\hline$C_{0, \text { sat }}$ & Saturation concentration in octanol $\left(\mu \mathrm{g} / \mathrm{m}^{3}\right)$ \\
\hline$C_{p m}$ & Gas-phase SVOC concentration in porous material $\left(\mu \mathrm{g} / \mathrm{m}^{3}\right)$ \\
\hline$C_{s}$ & Concentration of SVOCs on sink surfaces $\left(\mu \mathrm{g} / \mathrm{m}^{2}\right)$ \\
\hline$C_{s s l}$ & Concentration of SVOCs associated with skin-surface lipids $\left(\mu \mathrm{g} / \mathrm{m}^{3}\right)$ \\
\hline$C_{t}$ & Particle- and gas-phase SVOC concentration in the gas phase $\left(\mu \mathrm{g} / \mathrm{m}^{3}\right)$ \\
\hline$C R_{S}$ & Rate of contact with sink surfaces $\left(\mathrm{m}^{2} / \mathrm{h}\right)$ \\
\hline$d$ & Exposure duration $(\mathrm{h})$ \\
\hline$D_{a}$ & Diffusion coefficient of the SVOC in air $\left(\mathrm{m}^{2} / \mathrm{h}\right)$ \\
\hline$D_{m}$ & Diffusion coefficient of the SVOC in clothing material $\left(\mathrm{m}^{2} / \mathrm{h}\right)$ \\
\hline$D I$ & Daily intake $(\mu \mathrm{g} / \mathrm{kg})$ \\
\hline$E$ & Emission rate of SVOCs from source materials $\left(\mu \mathrm{g} /\left(\mathrm{m}^{2} \cdot \mathrm{h}\right)\right)$ \\
\hline$E F$ & Exposure frequency $(1 / \mathrm{h})$ \\
\hline$E X_{\text {cloth_d }}$ & Dermal exposure rate to clothing $(\mu \mathrm{g} / \mathrm{h})$ \\
\hline$E x_{\text {dust_ing }}$ & Dust ingestion exposure rate $(\mu \mathrm{g} / \mathrm{h})$ \\
\hline$E x_{\text {gas }} d$ & Transdermal exposure rate from the gas phase $(\mu \mathrm{g} / \mathrm{h})$ \\
\hline$E x_{i n h}$ & Inhalation exposure rate $(\mu \mathrm{g} / \mathrm{h})$ \\
\hline Ex $x_{\text {mouthing }}$ & Mouthing exposure rate for mouthing of source $(\mu \mathrm{g} / \mathrm{h})$ \\
\hline EX $X_{\text {mouthing_other }}$ & $\begin{array}{l}\text { Mouthing exposure rate for mouthing of objects with sink surfaces } \\
(\mu \mathrm{g})\end{array}$ \\
\hline Expart_d & $\begin{array}{l}\text { Transdermal exposure rate for particles adhered to exposed skin } \\
(\mu \mathrm{g} / \mathrm{h})\end{array}$ \\
\hline EX $X_{\text {Source_d }}$ & Exposure rate for direct contact of source with the skin $(\mu \mathrm{g} / \mathrm{h})$ \\
\hline$E_{\text {Source_ing }}$ & Source ingestion exposure rate $(\mu \mathrm{g} / \mathrm{h})$ \\
\hline$E x_{\text {surf } d}$ & $\begin{array}{l}\text { Transdermal exposure rate for dermal contact with sink surfaces } \\
(\mu \mathrm{g} / \mathrm{h})\end{array}$ \\
\hline$F$ & $\begin{array}{l}\text { Particle-phase concentration of SVOCs in indoor environments } \\
\left(\mu \mathrm{g} / \mathrm{m}^{3}\right)\end{array}$ \\
\hline$F_{\text {out }}$ & Outdoor particle-phase concentration of SVOCs $\left(\mu \mathrm{g} / \mathrm{m}^{3}\right)$ \\
\hline$f_{A}$ & Fraction of chemical available for uptake (-) \\
\hline$f_{\text {om_dust }}$ & Fraction of organic matter in dust (-) \\
\hline$f_{\text {om_part }}$ & Fraction of organic matter associated with airborne particles (-) \\
\hline$f_{\text {ret }}$ & Retention fraction of a source (-) \\
\hline$H$ & Henry's law constant $\left(\mathrm{m}^{3} \cdot \mathrm{Pa} / \mathrm{mol}\right)$ \\
\hline$h_{m, s}$ & Mass transfer coefficient for the sink (non-source) surface $(\mathrm{m} / \mathrm{h})$ \\
\hline$h_{m}$ & Mass transfer coefficient for the surface of a source $(\mathrm{m} / \mathrm{h})$ \\
\hline
\end{tabular}




\begin{tabular}{|c|c|}
\hline$I R_{\text {dust }}$ & Dust intake rate $(\mathrm{g} / \mathrm{h})$ \\
\hline$I R_{\text {inh }}$ & Inhalation intake rate $\left(\mathrm{m}^{3} / \mathrm{h}\right)$ \\
\hline$I R_{\text {source }}$ & Source intake rate $(\mathrm{g} / \mathrm{h})$ \\
\hline$j$ & Represents a specific SVOC out of $N$ SVOCs (-) \\
\hline Jource_ssl & Flux from source to skin-surface lipids $\left(\mu \mathrm{g} /\left(\mathrm{m}^{2} \cdot \mathrm{h}\right)\right)$ \\
\hline$J_{s s l \_c}$ & Flux from skin-surface lipids to dermal capillaries $\left(\mu \mathrm{g} /\left(\mathrm{m}^{2} \cdot \mathrm{h}\right)\right)$ \\
\hline$k_{p_{-} g}$ & Transdermal permeability coefficient from the gas phase $(\mathrm{m} / \mathrm{h})$ \\
\hline$k_{p_{-} s s l}$ & $\begin{array}{l}\text { Transdermal permeability coefficient from the skin-surface lipids to } \\
\text { dermal capillaries }(\mathrm{m} / \mathrm{h})\end{array}$ \\
\hline$K_{\text {dust }}$ & Dust/gas partition coefficient $\left(\mathrm{m}^{3} / \mathrm{g}\right)$ \\
\hline$K_{a w}$ & Air/water partition coefficient (-) \\
\hline$K_{c a}$ & Clothing/gas partition coefficient (-) \\
\hline$K_{m}$ & Dust/material partition coefficient $\left(\mathrm{m}^{3} / \mathrm{g}\right)$ \\
\hline$K_{o a}$ & Octanol/air partition coefficient (-) \\
\hline$K_{o w}$ & Octanol/water partition coefficient (-) \\
\hline$K_{p}$ & Gas/particle partition coefficient of SVOCs $\left(\mathrm{m}^{2} / \mathrm{\mu g}\right)$ \\
\hline$K_{s}$ & Sink surface/gas partition coefficient (m) \\
\hline$K_{s s l}$ & Partition coefficient between skin-surface lipids (SSL) and clothing (-) \\
\hline$L$ & Thickness of the porous material $(\mathrm{m})$ \\
\hline$L_{c}$ & Characteristic length $(\mathrm{m})$ \\
\hline$L_{m}$ & Thickness of clothing material $(\mathrm{m})$ \\
\hline$M_{s}$ & Mass loading of settled dust on sink (non-source) surfaces $\left(\mu \mathrm{g} / \mathrm{m}^{2}\right)$ \\
\hline$M_{S S}$ & Mass loading of settled dust on source surface $\left(\mu \mathrm{g} / \mathrm{m}^{2}\right)$ \\
\hline$M R$ & Migration rate during mouthing $\left(\mathrm{g} /\left(\mathrm{m}^{2} \cdot \mathrm{h}\right)\right)$ \\
\hline$m_{x}$ & Dust mass concentration at the depth of $x\left(\mu \mathrm{g} / \mathrm{m}^{3}\right)$ \\
\hline$n$ & Freundlich constant (-) \\
\hline$N$ & Number of SVOCs considered (-) \\
\hline$P_{\text {dust }, s}$ & $\begin{array}{l}\text { Concentration of SVOCs in the dust settled on the sink (non-source) } \\
\text { surfaces }(\mu \mathrm{g} / \mathrm{g})\end{array}$ \\
\hline$P_{\text {dust }}$ & $\begin{array}{l}\text { Concentration of SVOCs in the dust settled on the source } \\
\text { surface }(\mu \mathrm{g} / \mathrm{g})\end{array}$ \\
\hline$P_{p}$ & Size-dependent particle penetration factor (-) \\
\hline$p_{s}$ & Saturation vapor pressure of pure SVOCs $(\mathrm{Pa} ; \mathrm{mmHg})$ \\
\hline$Q$ & Ventilation rate $\left(\mathrm{m}^{3} / \mathrm{h}\right)$ \\
\hline$q_{\text {part_skin }}$ & Transfer rate from particles adhered to skin $(\mathrm{m} / \mathrm{h})$ \\
\hline$R$ & Universal gas constant $\left(\mathrm{m}^{3} \cdot \mathrm{Pa} /(\mathrm{K} \cdot \mathrm{T})\right)$ \\
\hline$R_{p}$ & Size-dependent particle resuspension rate $(1 / \mathrm{h})$ \\
\hline $\operatorname{Re}$ & Reynolds number \\
\hline$r_{\text {uptake }}$ & Chemical uptake rate $(1 / \mathrm{h})$ \\
\hline$S$ & Generation rate of particles from indoor sources $(\mu \mathrm{g} / \mathrm{h})$ \\
\hline Sc & Schmidt Number \\
\hline Sh & Sherwood Number \\
\hline$t$ & Time (h) \\
\hline$T$ & Temperature (K) \\
\hline TSP & Mass concentration of total suspended particles in the room $\left(\mu \mathrm{g} / \mathrm{m}^{3}\right)$ \\
\hline TSP $P_{\text {out }}$ & Mass concentration of total suspended particles outdoors $\left(\mu \mathrm{g} / \mathrm{m}^{3}\right)$ \\
\hline$V$ & Volume of the room $\left(\mathrm{m}^{3}\right)$ \\
\hline
\end{tabular}




\begin{tabular}{|c|c|}
\hline$v_{d}$ & $\begin{array}{l}\text { Size-dependent particle deposition velocity }(\mathrm{m} / \mathrm{h}) \text {. Could be } v_{d v}, v_{d u} \text {, or } \\
v_{d d} \text { depending on the orientation of the surface. }\end{array}$ \\
\hline$v_{d v}$ & Size-dependent particle deposition velocity to a vertical wall $(\mathrm{m} / \mathrm{h})$ \\
\hline$v_{d u}$ & $\begin{array}{l}\text { Size-dependent particle deposition velocity to an upward-facing } \\
\text { horizontal surface }(\mathrm{m} / \mathrm{h})\end{array}$ \\
\hline$v_{d d}$ & $\begin{array}{l}\text { Size-dependent particle deposition velocity to a downward-facing } \\
\text { horizontal surface }(\mathrm{m} / \mathrm{h})\end{array}$ \\
\hline$w_{0}$ & SVOC mass fraction in the source $(\mu \mathrm{g} / \mathrm{g})$ \\
\hline$w_{\text {dust }}$ & SVOC mass fraction in dust settled on source surfaces $(\mu \mathrm{g} / \mathrm{g})$ \\
\hline$W_{d u s t, s}$ & $\begin{array}{l}\text { SVOC mass fraction in dust settled on sink (non-source) surfaces } \\
(\mu \mathrm{g} / \mathrm{g})\end{array}$ \\
\hline$x$ & Depth from the surface of the material $(\mathrm{m})$ \\
\hline$y\left(\right.$ or $\left.C_{g}\right)$ & Gas-phase concentration of SVOCs in indoor environments $\left(\mu \mathrm{g} / \mathrm{m}^{3}\right)$ \\
\hline$y_{0}$ & $\begin{array}{l}\text { Gas-phase concentration of SVOCs in the layer immediately adjacent } \\
\text { to the source }\left(\mu \mathrm{g} / \mathrm{m}^{3}\right)\end{array}$ \\
\hline$Y_{\text {out }}$ & Outdoor gas-phase concentration of SVOCs $\left(\mu \mathrm{g} / \mathrm{m}^{3}\right)$ \\
\hline$y_{s}$ & $\begin{array}{l}\text { Gas-phase concentration of SVOCs in the layer immediately adjacent } \\
\text { to the non-source surfaces }\left(\mu \mathrm{g} / \mathrm{m}^{3}\right)\end{array}$ \\
\hline$\delta$ & Thickness of the organic film (m) \\
\hline$\delta_{0}$ & $\begin{array}{l}\text { Critical film thickness at which adsorption transforms to absorption } \\
\text { (m) }\end{array}$ \\
\hline$\varepsilon$ & Porosity of material (-) \\
\hline$\rho_{\text {dust }}$ & Density of dust $\left(\mu \mathrm{g} / \mathrm{m}^{3}\right)$ \\
\hline$\rho_{\text {part }}$ & Density of airborne particles $(\mu \mathrm{g} / \mathrm{m}$ \\
\hline$\rho_{\text {source }}$ & Density of source $\left(\mu \mathrm{g} / \mathrm{m}^{3}\right)$ \\
\hline
\end{tabular}




\section{2) List of Consensus Points}

Consensus Point 1: To address challenges posed by exposure modeling, mechanistic models are preferred. Mechanistic models are based on physicochemical principles and are thus more generalizable in contrast to empirical models. They can be selected and varied in their level of complexity based on the application.

Diverse data sets and the estimation of key input parameters using structure-based or other predictive relationships can be included in mechanistic modeling approaches. It is clear that mechanistic models have to be validated, and input parameter development and validation still require good data, which often does not exist.

Consensus Point 2: The environmental compartments relevant to modeling chemical exposure indoors are the gas phase, airborne particles, settled dust and exposed indoor surfaces, including those of the occupants. Additionally, clothing exposed to indoor air can serve as exposure mediator potentially increasing or decreasing dermal uptake.

Consensus Point 3: The assumption of equilibrium between gas phase, particle phase, dust and surfaces is a prerequisite for simpler SVOC models. However, this assumption has to be treated with caution. The greater the capacity of an environmental compartment, the longer it will take for that compartment to reach equilibrium with other compartments.

Consensus Point 4: SVOC emissions are assumed to be externally controlled, thus internal diffusion is neglected and the source is considered as non-depleting. Clothing is a special case due to differences in time scales, thus internal diffusion and source depletion may be relevant.

Consensus Point 5: It is assumed that the air in the indoor environment is well-mixed. An exception might be indoor air inside closed spaces such as closets and cabinets, which should be considered separately as needed.

Consensus Point 6: For some SVOCs emitted by indoor sources, outdoor air concentrations are low and can thus be neglected in exposure assessments. In other cases, indoor and outdoor concentrations may 
be comparable, thus the question of the relevance of outdoor contributions has to be taken into account and concentrations of SVOCs in the infiltrating air may have to be considered.

Consensus Point 7: Exposure can occur immediately via dermal contact with or ingestion of the source (Direct Exposure). Alternatively, emission from the source to environmental compartments occurs first, followed by transport and chemical transformations, resulting in the SVOC's presence in one or more compartments from which exposure occurs (Indirect Exposure).

Consensus Point 8: Mechanistically consistent source emission categories, derived from a continuum of sources, serve as the starting point for modeling exposure to SVOCs emitted by sources in the indoor environment. These categories are: solid, soft, frequent contact, applied, sprayed and high temperature. Consensus Point 9: Stationary non-porous sources that are not frequently handled or touched (e.g., furniture, TVs, or vinyl flooring) have large emitting surface areas relative to the volume of most indoor environments or to the area that might come in contact with an exposed person. Exposure to SVOCs present in these solid sources mainly occurs by Indirect Exposure.

Consensus Point 10: Soft sources include cushions, mattresses, foams, carpets and clothing. Exposure to soft sources can occur both via Direct Exposure due to frequent close contact of a person to these sources and via Indirect Exposure due to their often large emitting surface areas.

Consensus Point 11: Exposure to certain SVOCs in sources that are frequently handled (e.g., electronic devices, toys) or mouthed by children (e.g., teethers) is more likely to occur via Direct Exposure. The emission category for this type of source is frequent contact.

Consensus Point 12: A liquid source that is directly applied to the body (e.g., body lotion, shampoo) is mainly linked to Direct Exposure. If the source is applied to a surface or is exposed to the indoor air (e.g., paint or detergent), Indirect Exposure dominates. Applied sources have to be considered pulse emission sources and thus require dynamic modeling approaches.

Consensus Point 13: A source that is sprayed towards the body can cause both Direct and Indirect Exposure (e.g., insect repellant). If the source is sprayed away from a person (e.g., air freshener), Indirect Exposure 
contributes more. Both cases are pulse emissions and thus dynamic equations to model emission, transport and exposure are necessary.

Consensus Point 14: Combustion or heating processes such as burning a candle or cooking contribute mostly to Indirect Exposure. The relevant emission category is high temperature. This type of emission is a pulse emission that needs to include dynamic emission and chemical reactions.

Consensus Point 15: For modeling SVOC behavior in indoor environments, chemical transformations (e.g., oxidation, hydrolysis) should be discussed, even if they are not addressed quantitatively.

Consensus Point 16: Transport, partitioning and reactivity of SVOCs indoors are highly complex processes and not completely understood. 
3) Mechanistic Modeling Framework to Predict Exposure to SVOCs

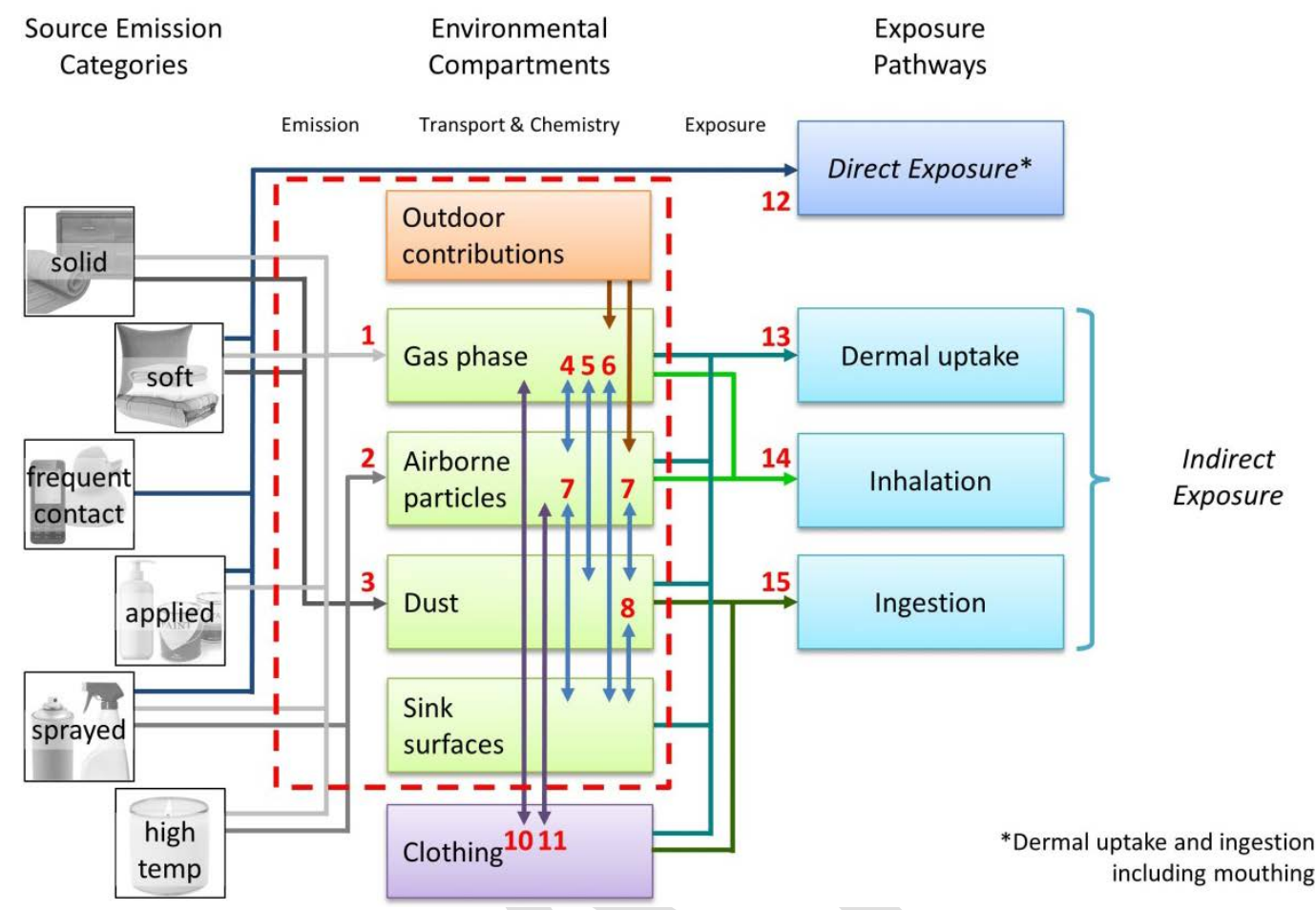

Figure S1: Dominant exposure pathways for SVOCs in indoor environments.

The red numbers refer to the equations listed below.

\section{4) Emission and Transport Modeling Equations}

\section{Emission into the gas phase}

a. From solid sources, soft sources, and dried liquid sources:

$$
E=h_{m} \cdot\left(y_{0}-y\right)
$$

Note: It is assumed that internal diffusion is negligible.

b. From applied sources (pulse emission):

Dynamic model, research needed

c. From sprayed sources (pulse emission):

Model development needed

d. From high temperature sources (pulse emission): 
Model development needed

\section{Emission to airborne particles}

a. From sprayed sources (pulse emission):

Model development needed

b. From high temperature sources (pulse emission):

Model development needed

\section{Emission to settled dust}

From both solid and soft sources and including emission into the gas phase:

$$
E=h_{m} \cdot\left(y_{0}-y\right)+v_{d} \cdot T S P \cdot P_{d u s t}-v_{d} \cdot F
$$

\section{Gas/particle partitioning}

$$
F=K_{p} \cdot T S P \cdot y
$$

Note: Instant equilibrium is assumed.

\section{Dust/gas partitioning}

a. For dust settled on source surfaces:

$$
P_{\text {dust }}=K_{\text {dust }} \cdot y_{0}
$$

Note: Alternatively, partitioning between dust and source material can be described using the dust/material partition coefficient $K_{m}$. See Liu et al. $2016^{1}$ for details.

b. For dust settled on sink surfaces:

$$
P_{d u s t, s}=K_{d u s t} \cdot y_{s}
$$

\section{Surface/gas partitioning for sink surfaces}

a. For solid sink surfaces:

$$
C_{s}=K_{s} \cdot y_{s}
$$

b. For soft sink surfaces:

$$
\left[\varepsilon+(1-\varepsilon) \cdot K_{s}+K_{d u s t} \cdot m_{x}\right] \frac{\partial C_{p m}}{\partial t}=\varepsilon \cdot D_{a} \frac{\partial^{2} C_{p m}}{\partial x^{2}}
$$




$$
C_{p m}=0 \text { for } t=0,0 \leq x \leq L ; \quad \frac{\partial C_{p m}}{\partial t}=0 \text { for } t>0, x=L ; \quad C_{p m}=y_{s} \text { for } t>0, x=0
$$

c. In the presence of an organic surface film:

$$
\begin{gathered}
\frac{d C_{s, j}}{d t}=h_{m, s, j}\left(y_{j}-\frac{C_{s, j}}{\delta \cdot K_{o a}}\right)+v_{d} \cdot F \\
\delta=\delta_{0}+\sum_{j=1}^{N} \frac{C_{s, j}}{\rho_{j}}
\end{gathered}
$$

Note: See Eichler et al. $2019^{2}$ for further detail.

\section{Mass balance for particle transport}

$$
\begin{aligned}
& V \frac{d T S P}{d t}=Q \cdot P_{p} \cdot T S P_{\text {out }}-Q \cdot T S P-v_{d} \cdot T S P \cdot\left(A_{s}+A_{S S}\right)+R_{p} \cdot M_{S} \cdot A_{s}+R_{p} \cdot M_{S S} \cdot A_{s S}+S
\end{aligned}
$$

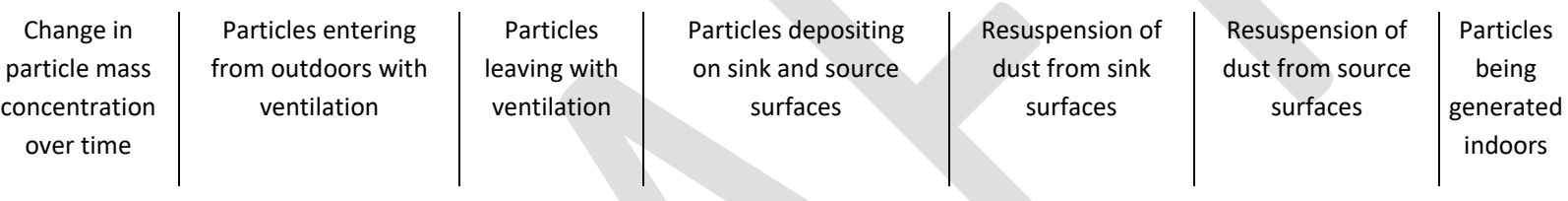

$$
\begin{aligned}
& \frac{d M_{S}}{d t}=v_{d} \cdot T S P-R_{p} \cdot M_{S S} \quad \text { or } \quad \frac{d M_{S}}{d t}=v_{d} \cdot T S P-R_{p} \cdot M_{S}
\end{aligned}
$$

\section{Mass balance for dust settled on sink surfaces}

$$
\frac{d\left(C_{s}+M_{s} \cdot P_{d u s t, s}\right)}{d t}=h_{m, s} \cdot\left(y-y_{s}\right)+v_{d} \cdot F-R_{p} \cdot M_{s} \cdot P_{d u s t, s}
$$

\begin{tabular}{c|c|c|c|c|c|c|c|}
$\begin{array}{c}\text { Change in SVOC concentration } \\
\text { on sink surface and dust over } \\
\text { time }\end{array}$ & $\begin{array}{c}\text { Emission from the } \\
\text { sink surface into the } \\
\text { gas phase }\end{array}$ & $\begin{array}{c}\text { SVOC concentration } \\
\text { in dust deposited } \\
\text { on sink surface }\end{array}$ & $\begin{array}{c}\text { SVOC concentration } \\
\text { in resuspended dust }\end{array}$
\end{tabular}

\section{General mass balance for indoor SVOCs}

$$
\begin{aligned}
V \frac{d y}{d t}+V \frac{d F}{d t}=Q \cdot & \left(y_{\text {out }}+F_{\text {out }}\right)-Q \cdot(y+F)+h_{m} \cdot A_{s s} \cdot\left(y_{0}-\mathrm{y}\right)-h_{m, s} \cdot A_{s} \cdot\left(y-y_{s}\right) \\
& -v_{d} \cdot F \cdot\left(A_{s s}+A_{s}\right)+R_{p} \cdot M_{s s} \cdot P_{d u s t} \cdot A_{s s}+R_{p} \cdot M_{s} \cdot P_{d u s t, s} \cdot A_{s}
\end{aligned}
$$

Note: If outdoor concentrations are assumed to be negligible, $y_{\text {out }}$ and $F_{\text {out }}$ equal 0 , respectively.

Note: This mass balance does not include clothing-mediated effects.

\section{Clothing/gas partitioning}


a. General approach:

$$
\frac{\partial C_{m}}{\partial t}=D_{m} \frac{\partial^{2} C_{m}}{\partial x^{2}}
$$

Boundary condition at clothing surface:

$$
-\left.D_{m} \frac{\partial C_{m}}{\partial x}\right|_{x=L_{m}}=h_{m}\left(y-\frac{C_{m}}{K_{c a}}\right)
$$

b. If diffusion in clothing can be ignored:

$$
\frac{\partial C_{m}}{\partial t}=h_{m}\left(y-\frac{C_{m}}{L_{m} \cdot K_{c a}}\right)
$$

Note: The diffusivity within the clothing material can be ignored, if the characteristic time required for clothing to reach equilibrium with the gas phase is much larger than the time required for diffusion to occur: $\frac{K_{c a} L_{m}}{h_{m}} \gg \frac{K_{c a} L_{m}^{2}}{D_{m}}$ (alternatively, if $\frac{h_{m} \cdot L_{m}}{D_{m}} \gg 1$ ).

Note: See Cao et al. $2016^{3}$ for further detail.

\section{Clothing/particle partitioning}

\section{Model development needed}

\section{5) Exposure Modeling Equations}

Note: The exposure modeling equations (Eq. 12-15) listed below do not account for different bioaccessibilities and have thus considered worst case scenarios. However, we recommend applying bioaccessibility factors if these are available. ${ }^{4,5}$

General conversion from exposure rate to daily intake:

$$
D I=\frac{E x \cdot d}{b w}
$$

\section{Direct Exposure}

a. Dermal uptake via direct contact with a source:

Transfer from a solid source to skin surface: $E x_{\text {source_d }}=J_{\text {source_ssl }} \cdot A_{\text {contact }}$ 
Transfer from liquid source to skin surface: Ex $_{\text {source_d }}=w_{0} \cdot A R_{\text {source }} \cdot f_{A} \cdot f_{\text {ret }}$

Note: See Huang et al. $2017^{6}$, CHAP $2014^{7}$ and Wormuth et al. $2006^{8}$ for example approaches.

Transfer from skin surface to dermal capillaries: $J_{s s l_{-} c}=C_{s s l} \cdot k_{p_{-} s s l}$

b. Ingestion of a source:

$$
\text { Ex } x_{\text {source_ing }}=w_{0} \cdot I R_{\text {source }}
$$

c. Mouthing of a source:

$$
E x_{\text {mouthing }}=w_{0} \cdot A_{\text {mouthing }} \cdot M R \cdot E F \cdot f_{A} \cdot d
$$

\section{Dermal uptake}

a. From the gas phase to dermal capillaries:

$$
E x_{g a s_{-} d}=C_{g} \cdot k_{p_{-} g} \cdot A_{\text {exp }}
$$

Note: See Weschler and Nazaroff $2014^{9}$ for the calculation of $k_{p_{-} g}$.

Note: See Gong et al. $2014^{10}$ and Morrison et al. $2016^{11}$ for a dynamic modeling approach.

b. From airborne particles or dust particles:

$$
E x_{\text {part_d }}=F \cdot A_{\text {exp }} \cdot q_{\text {part_skin }} \cdot f_{A}
$$

Note: See Wormuth et al. $2006^{8}$ and Giovanoulis et al. $2018^{12}$ for values of $f_{A}$.

Note: $F$ should be replaced by $P_{\text {dust, }}$ for dust from sink surfaces and by $P_{\text {dust, }}$ for dust from source surfaces.

c. From sink surfaces:

$$
E x_{\text {surf_d }}=C_{S} \cdot C R_{S} \cdot f_{A}
$$

d. From clothing:

$$
\begin{gathered}
E x_{\text {cloth_d }}=C_{s s l} \cdot k_{p_{-} s s l} \cdot A_{\text {exp }} \\
C_{s s l}=K_{s s l} \cdot C_{m}
\end{gathered}
$$

Note: See Morrison et al. ${ }^{13}$ and Cao et al. $2018^{14}$ for more detail. Eq. $13 \mathrm{~d}$ is based on the assumption that the skin-surface lipids (SSL) are in equilibrium with the clothing. This is likely not the case for many 
SVOCs because the timescale for reaching equilibrium ${ }^{15}$ is often longer than the duration of contact between clothing and the skin-surface lipids. Thus, this equation describes a worst case scenario.

\section{Inhalation}

Inhalation of gas phase and airborne particles:

$$
\begin{gathered}
E x_{i n h}=C_{t} \cdot I R_{i n h} \\
\text { with } C_{t}=C_{g}+F
\end{gathered}
$$

\section{Ingestion}

a. Ingestion of dust:

$$
E x_{\text {dust_ing }}=w_{\text {dust }} \cdot I R_{\text {dust }}
$$

Note: For dust from sink surfaces, $w_{\text {dust }}$ should be replaced by $w_{\text {dust }, s .}$

Note: $w_{\text {dust }}$ can be approximated with $f_{\text {om_dust }}$.

b. Mouthing of objects/exposed clothing and hand-to-mouth:

See $13 c . f_{A}$ might vary.

Note: Empirical equations available in Isaacs et al. $2014^{16}$ and Huang et al. $2017^{6}$.

\section{6) Estimation Approaches for Model Parameters}

\section{Saturation vapor pressure $\left(p_{s}\right)$}

Antoine equation (A, B, C are substance-specific coefficients) ${ }^{17}$ :

$$
\log \left(p_{s}\right)=A-\frac{B}{C+T}
$$

Note: See Vyazovkin, Koga, and Schick $2018^{18}$ for an overview of experimental methods to determine the vapor pressure of chemicals with different volatilities. Wu et al. $2016^{19}$ developed a method to measure vapor pressure for SVOCs.

\section{Octanol/air partition coefficient $\left(K_{o a}\right)$}

$$
K_{o a}=\frac{K_{o w}}{K_{a w}}=\frac{K_{o w} \cdot R \cdot T}{H}
$$


Relationship between $p_{s}$ and $K_{o a}$ :

$$
K_{o a}=\frac{C_{o, s a t}}{p_{s} /(R T)}=\frac{C_{o, s a t}}{C_{a, s a t}}
$$

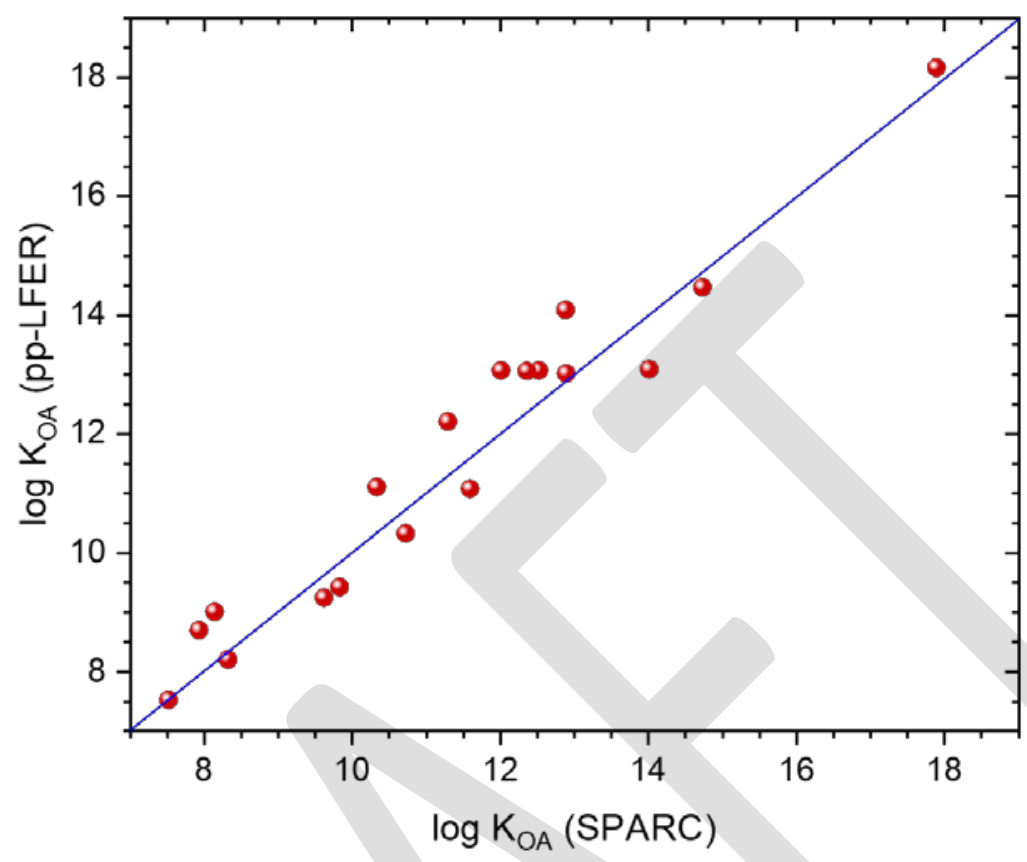

Figure S2: Comparison of $K_{\text {oa }}$ values calculated by SPARC (ARChem) and the poly-parameter Linear-Free-Energy-Relationship (pp-LFER) ${ }^{20}$ (LSER Database). The compounds in ascending order of $K_{\mathrm{oa}}$ (SPARC) values are DMP, DiBA, DnBA, DEP, DiBP, DnBP, TPP, DPP, DEHA, BBzP, TEHP, DINA, DEHTP, DINCH, DEHP, DINP, DPHP, and TOTM.

\section{Gas-phase concentration immediately adjacent to the source $\left(y_{0}\right)$}

General relationship between $y_{0}, p_{s}$, and $C_{0}$ :

$$
\begin{gathered}
y_{0}=\gamma \cdot w_{0} \cdot p_{s} \\
\text { with } w_{0}=\frac{c_{0}}{\rho_{\text {product }}}
\end{gathered}
$$

For phthalates and phthalates alternatives (Eichler et al. 2018 ${ }^{21}$ ):

$$
y_{0}=3.70 \cdot w_{0} \cdot p_{s}
$$

For phthalates and organophosphate flame retardants (Liang et al. 2018 22 ): 


$$
y_{0}=3.405 \cdot w_{0} \cdot p_{s}
$$

\section{Mass-transfer coefficient $\left(h_{m}\right)$}

$$
\begin{gathered}
h_{m} \text { or } h_{m, s}=S h \cdot \frac{D_{a}}{L_{c}} \\
S h=0.664 \cdot R e^{\frac{1}{2}} \cdot S c^{1 / 3}
\end{gathered}
$$

Note: This estimation of $h_{m}$ and $h_{m, s}$ uses the correlations in Axley $1991^{23}$. Typically, the average air velocity across interior surfaces is in the range of $0.01-0.16 \mathrm{~m} / \mathrm{s}$ as reported by Huang et al. $2004^{24}$. This value could be an underestimation, thus specific air velocity and characteristic lengths should be selected when estimating the mass transfer coefficient for particular indoor cases.

\section{Gas/particle partition coefficient $\left(K_{\mathrm{p}}\right)$}

Definition (Pankow 199425):

$$
K_{p}=\frac{F / T S P}{C_{g}}
$$

Extended by Finizio et al. $1997^{26}$ :

$$
\begin{gathered}
K_{p}=\frac{f_{\text {om_part }} \times K_{o a}}{\rho_{\text {part }}} \\
\log \left(K_{p}\right)=\log \left(K_{\text {oa }}\right)+\log \left(f_{\text {om_part }}\right)-11.91
\end{gathered}
$$

Another method (Naumova et al. $2003^{27}$, regression based on PAH data in atmosphere with $\mathrm{PM}_{2.5}$ ):

$$
\log \left(K_{p}\right)=-0.860 \log \left(p_{s}\right)-4.67
$$

See Salthammer and Schripp $2015^{28}$ and Salthammer and Goss $2019^{20}$ for more information on the determination of $K_{p}$.

\section{Dust/gas partition coefficient ( $\left.K_{\text {dust }}\right)$}

$$
K_{d u s t}=\frac{P_{d u s t}}{C_{g}}=\frac{f_{o m \_d u s t} \times K_{o a}}{\rho_{\text {dust }}}
$$

\section{Non-source surface/gas partition coefficient $\left(K_{s}\right)$}

a. Wood floors, ceiling and walls, and furniture (Xu et al. $2009^{29}$, regression for phthalates):

$$
\log \left(K_{S}\right)=-0.779 \log \left(p_{s}\right)-1.93
$$


b. Windows, mirrors, tile and ceramic fixtures:

Freundlich isotherm fitted by Xu and Little $(2006)^{30}$ for DEHP: $K_{\mathrm{s}}=3800, n=1.5$

c. Carpet (Xu et al. $2009^{29}$, regression for phthalates):

$$
\log \left(K_{S}\right)=-0.627 \log \left(p_{s}\right)-1.08
$$

d. Stainless steel (Liang et al. $2018^{31}$ ):

Freundlich isotherm fitted for TCEP: $K_{\mathrm{s}}=31.6, n=0.24$

Freundlich isotherm fitted for TCPP: $K_{\mathrm{s}}=67.1, n=0.26$

e. Polyurethane foam (Liang et al. $2019^{32}$ ) depending on the temperature:

$$
\begin{aligned}
& \text { For TCEP: } K_{\mathrm{S}}=2 \cdot 10^{-18} \cdot \mathrm{T}^{0.5} \cdot \mathrm{e}^{17335 / \mathrm{T}} \\
& \text { For TCIPP: } K_{\mathrm{S}}=2 \cdot 10^{-16} \cdot \mathrm{T}^{0.5} \cdot \mathrm{e}^{15468 / \mathrm{T}}
\end{aligned}
$$

f. See also Liu et al. $2014^{33}$ and Liu et al. $2016^{34}$ for $K_{\mathrm{s}}$ values for polychlorinated biphenyls (PCBs) and organophosphorus flame retardants (OPFRs) for a variety of materials.

\section{Gas/clothing partition coefficient $\left(K_{c a}\right)$}

a. See Morrison et al. $2018^{35}$ for gas/clothing partition coefficients for PCBs in cotton and polyester, and in blends of polyester, cotton, viscose/rayon, and/or elastane.

b. See Cao et al. $2016^{3}$ for gas/clothing partition coefficients for diisobutyl phthalate (DiBP), di-n-butyl phthalate (DnBP), and bis(2-ethylhexyl) phthalate (DEHP) in cotton clothing.

c. See Morrison et al. $2015^{36}$ for gas/clothing partition coefficients for diethyl phthalate (DEP) and DnBP in cotton clothing. 


\section{7) Decision Tree}

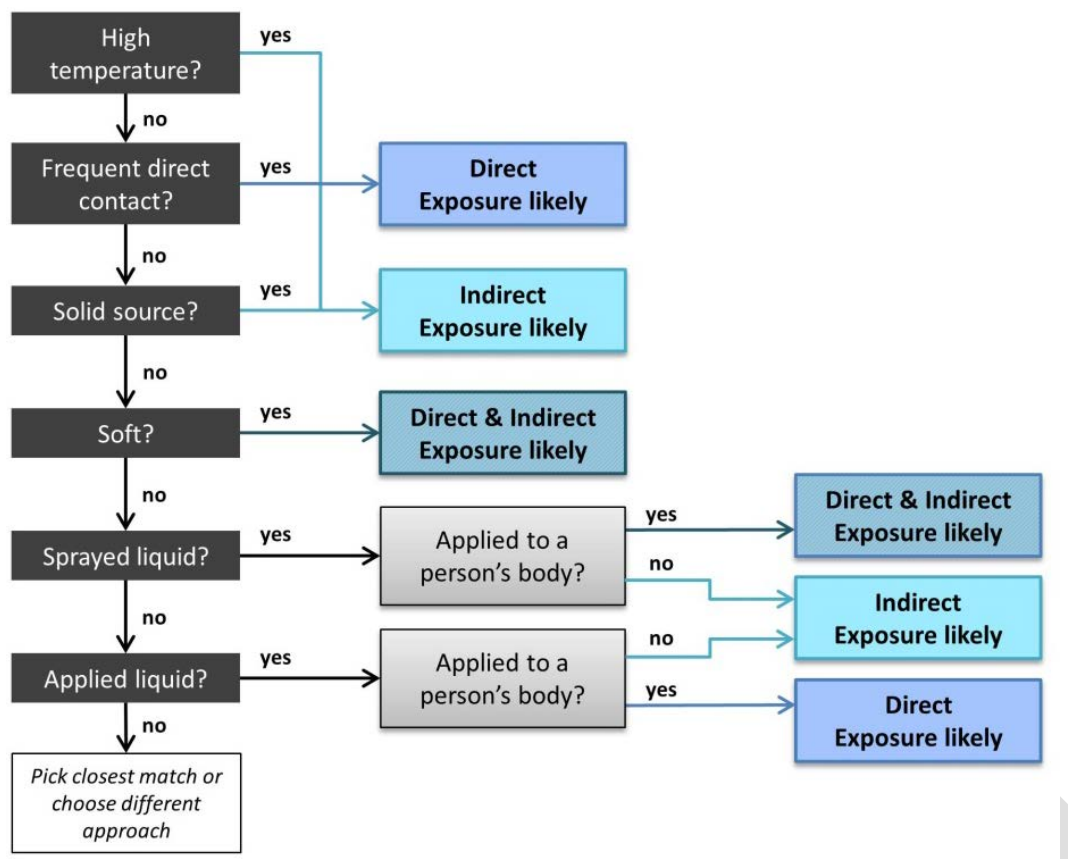

Figure S3: Decision tree for exposure mechanism selection based on source emission category. 


\section{$\underline{\text { References }}$}

1. Liu, X.; Guo, Z.; Krebs, K. A.; Greenwell, D. J.; Roache, N. F.; Stinson, R. A.; Nardin, J. A.; Pope, R. H., Laboratory Study of PCB Transport from Primary Sources to Settled Dust. Chemosphere 2016, 149, 6269.

2. Eichler, C. M. A.; Cao, J.; Isaacman-VanWertz, G.; Little, J. C., Modeling the Formation and Growth of Organic Films on Indoor Surfaces. Indoor Air 2019, 29, 17-29.

3. Cao, J.; Weschler, C. J.; Luo, J.; Zhang, Y., Cm-History Method, a Novel Approach to Simultaneously Measure Source and Sink Parameters Important for Estimating Indoor Exposures to Phthalates. Environ. Sci. Technol. 2016, 50, (2), 825-834.

4. Wei, W.; Bonvallot, N.; Gustafsson, Å.; Raffy, G.; Glorennec, P.; Krais, A.; Ramalho, O.; Le Bot, B.; Mandin, C., Bioaccessibility and bioavailability of environmental semi-volatile organic compounds via inhalation: A review of methods and models. Environ. Int. 2018, 113, 202-213.

5. Raffy, G.; Mercier, F.; Glorennec, P.; Mandin, C.; Le Bot, B., Oral bioaccessibility of semi-volatile organic compounds (SVOCs) in settled dust: A review of measurement methods, data and influencing factors. J. Hazard. Mater. 2018, 352, 215-227.

6. Huang, L.; Ernstoff, A. S.; Fantke, P.; Csiszar, S. A.; Jolliet, O., A review of models for near-field exposure pathways of chemicals in consumer products. Sci. Total Environ. 2017, 574, 1182-1208.

7. CHAP Chronic Hazard Advisory Panel on Phthalates and Phthalate Alternatives; U.S. Consumer Product Safety Commission: Bethesda, MD, 2014.

8. Wormuth, M.; Scheringer, M.; Vollenweider, M.; Hungerbühler, K., What are the sources of exposure to eight frequently used phthalic acid esters in Europeans? Risk Anal. 2006, 26, (3), 803-824. 9. Weschler, C. J.; Nazaroff, W. W., Dermal Uptake of Organic Vapors Commonly Found in Indoor Air. Environ. Sci. Technol. 2014, 48, 1230-1237.

10. Gong, M.; Zhang, Y.; Weschler, C. J., Predicting dermal absorption of gas-phase chemicals: transient model development, evaluation, and application. Indoor Air 2014, 24, 292-306.

11. Morrison, G. C.; Weschler, C. J.; Bekö, G., Dermal uptake directly from air under transient conditions: advances in modeling and comparisons with experimental results for human subjects. Indoor Air 2016, 26, (6), 913-924.

12. Giovanoulis, G.; Bui, T. T.; Xu, F.; Papadopoulou, E.; Padilla-Sanchez, J. A.; Covaci, A.; Haug, L. S.; Cousins, A. P.; Magnér, J.; Cousins, I. T.; de Wit, C. A., Multi-pathway human exposure assessment of phthalate esters and DINCH. Environ. Int. 2018, 112, 115-126.

13. Morrison, G. C.; Weschler, C. J.; Bekö, G., Dermal uptake of phthalates from clothing: Comparison of model to human participant results. Indoor Air 2017, 27, (3), 642-649.

14. Cao, J.; Zhang, X.; Zhang, Y., Predicting dermal exposure to gas-phase semi-volatile organic compounds (SVOCs): an improved description of SVOC mass transfer between clothing and skin surface lipids. Environ. Sci. Technol. 2018, 52, 4676-4683.

15. Weschler, C. J.; Nazaroff, W. W., Semivolatile organic compounds in indoor environments. Atmos. Environ. 2008, 42, (40), 9018-9040.

16. Isaacs, K. K.; Glen, W. G.; Egeghy, P.; Goldsmith, M.-R.; Smith, L.; Vallero, D.; Brooks, R.; Grulke, C. M.; Özkaynak, H., SHEDS-HT: An Integrated Probabilistic Exposure Model for Prioritizing Exposures to Chemicals with Near-Field and Dietary Sources. Environ. Sci. Technol. 2014, 48, (21), 12750-12759.

17. Schwarzenbach, R. P.; Gschwend, P. M.; Imboden, D. M., Environmental Organic Chemistry. 2nd Edition ed.; John Wiley \& Sons, Inc.: Hoboken, NJ, 2003.

18. Handbook of Thermal Analysis and Calorimetry: Recent Advances, Techniques and Applications. 2nd Edition ed.; Elsevier: Amsterdam, NL, 2018; Vol. 6.

19. Wu, Y.; Eichler, C. M. A.; Chen, S.; Little, J. C., Simple Method To Measure the Vapor Pressure of Phthalates and Their Alternatives. Environ. Sci. Technol. 2016, 50, 10082-10088. 
20. Salthammer, T.; Goss, K.-U., Predicting the Gas/Particle Distribution of SVOCs in the Indoor Environment Using Poly Parameter Linear Free Energy Relationships. Environ. Sci. Technol. 2019, 53, 2491-2499.

21. Eichler, C. M. A.; Wu, Y.; Cao, J.; Shi, S.; Little, J. C., Equilibrium relationship between SVOCs in PVC products and the air in contact with the product. Environ. Sci. Technol. 2018, 52, (5), 2918-2925.

22. Liang, Y.; Liu, X.; Allen, M. R., Measurements of Parameters Controlling the Emissions of Organophosphate Flame Retardants in Indoor Environments. Environ. Sci. Technol. 2018, 52, (10), 58215829.

23. Axley, J. W., Adsorption Modelling for Building Contaminant Dispersal Analysis. Indoor Air 1991, 2, 147-171.

24. Huang, J. M.; Chen, Q.; Ribot, B.; Rivoalen, H., Modelling Contaminant Exposure in a Single-family House. Indoor and Built Environment 2004, 13, (1), 5-19.

25. Pankow, J. F., An Absorption Model of Gas/particle Partitioning of Organic Compounds in the Atmosphere. Atmos. Environ. 1994, 28, (2), 185-188.

26. Finizio, A.; Mackay, D.; Bidleman, T.; Harner, T., Octanol-air partition coefficient as a predictor of partitioning of semi-volatile organic chemicals to aerosols. Atmos. Environ. 1997, 31, (15), 2289-2296.

27. Naumova, Y. Y.; Offenberg, J. H.; Eisenreich, S. J.; Meng, Q.; Polidori, A.; Turpin, B. J.; Weisel, C. P.; Morandi, M. T.; Colome, S. D.; Stock, T. H.; Winer, A. M.; Alimokhtari, S.; Kwon, J.; Maberti, S.; Shendell, D.; Jones, J. W.; Farrar, C., Gas/particle distribution of polycyclic aromatic hydrocarbons in coupled outdoor/indoor atmospheres. Atmos. Environ. 2003, 37, (5), 703-719.

28. Salthammer, T.; Schripp, T., Application of the Junge- and Pankow-equation for estimating indoor gas/particle distribution and exposure to SVOCs. Atmos. Environ. 2015, 106, 467-476.

29. Xu, Y.; Cohen Hubal, E. A.; Clausen, P. A.; Little, J. C., Predicting Residential Exposure to Phthalate Plasticizer Emitted from Vinyl Flooring: A Mechanistic Analysis. Environ. Sci. Technol. 2009, 43, (7), 23742380.

30. Xu, Y.; Little, J. C., Predicting emissions of SVOCs from polymeric materials and their interaction with airborne particles. Environ. Sci. Technol. 2006, 40, (2), 456-461.

31. Liang, Y.; Liu, X.; Allen, M. R., Measuring and modeling surface sorption dynamics of organophosphate flame retardants on impervious surfaces. Chemosphere 2018, 193, (754-762), 754.

32. Liang, Y.; Liu, X.; Allen, M. R., The influence of temperature on the emissions of organophosphate ester flame retardants from polyisocyanurate foam: Measurement and modeling (supporting information). Chemosphere 2019, In press.

33. Liu, X.; Guo, Z.; Roache, N. F., Experimental method development for estimating solid-phase diffusion coefficients and material/air partition coefficients of SVOCs. Atmos. Environ. 2014, 89, 76-84.

34. Liu, X.; Allen, M. R.; Roache, N. F., Characterization of organophosphorus flame retardants' sorption on building materials and consumer products. Atmos. Environ. 2016, 140, 333-341.

35. Morrison, G.; Andersen, H. V.; Gunnarsen, L.; Voral, D.; Uhde, E.; Kolarik, B., Partitioning of PCBs from air to clothing materials in a Danish apartment. Indoor Air 2018, 28, (1), 188-197.

36. Morrison, G. C.; Li, H.; Mishra, S.; Buechlein, M., Airborne phthalate partitioning to cotton clothing. Atmos. Environ. 2015, 115, 149-152. 